\title{
Characterization of npf mutants identifying developmental genes in Physarum
}

\author{
Lilianna Solnica-Krezel, ${ }^{1} \dagger$ Juliet Bailey, ${ }^{2}$ Duncan P. Gruer, ${ }^{3}$ \\ Jacqueline M. Price, ${ }^{3}$ William F. Dove, ${ }^{1}$ Jennifer Dee $^{2}$ and Roger \\ W. Anderson ${ }^{3}$
}

Author for correspondence: Juliet Bailey. Tel: +44 116252 3414. Fax : +44116 2523378.

1 McArdle Laboratory for Cancer Research, 1400 University Avenue, Madison, WI 53706, USA

2 Department of Genetics, University of Leicester, University Road, Leicester LE1 7RH, UK

3 Department of Molecular Biology and Biotechnology, University of Sheffield, Sheffield S10 2TN, UK
In Physarum polycephalum, uninucleate haploid amoebae develop into macroscopic multinucleate plasmodia. Wild-type, sexual development is triggered when two amoebae carrying different alleles of matA fuse to form a zygote which develops into a diploid plasmodium. Mutations in the matA genetic region give rise to apogamic strains in which a single haploid amoeba can develop into a haploid plasmodium. An essential stage in both sexual and apogamic plasmodium formation is an extended cell cycle in uninucleate cells, which ends with the formation of a binucleate cell by mitosis without cytokinesis. Using a 'brute force' screening method, we have isolated mutants blocked in apogamic plasmodium development. Genetic analysis showed that the mutations we have identified were unlinked to matA, unlike mutations previously identified following an enrichment step. Most of the loci revealed by our screen were represented by only one allele, indicating that further screening should lead to the identification of additional genes required for plasmodium development. Phenotypic analysis showed that different mutants were blocked at different stages of plasmodium formation. Some of the mutations blocking apogamic development at an early stage, close to the start of the long cell cycle, failed to block sexual development in zygotes homozygous for the mutation. Since the two modes of plasmodium formation differ only in the initiation of development, these mutations presumably interfere with the initiation process. In the remaining mutants, in which both sexual and apogamic development were blocked, development first became abnormal towards the end of the long cell cycle. This suggested that the wildtype gene products were required by this time and was consistent with previous evidence that many changes in cellular organization and gene expression occur during the long cell cycle. Each of these mutants showed a different terminal phenotype and some aspects of plasmodium development occurred normally although others were blocked, suggesting that development involves multiple pathways rather than a dependent sequence of events. Phenotypic analysis of double mutants supported this conclusion and also revealed epistatic interactions, presumably due to blocks in the same pathway. In several of the mutants, terminally differentiated cells died by an apoptosis-like mechanism; since this was never observed in vegetative cells, it was presumably triggered by the failure of development. Phenotypic analyses of additional mutants will extend our understanding of the pathways involved in plasmodium development.

Keywords: Pbysarum polycephalum, protist, extended cell cycle, plasmodium development

†Present address: Cardiovascular Research Center, Massachusetts General Hospital - East 4, 13th St, Bldg 149, Charlestown, MA 02129, USA
Abbreviations: DAPI, 4',6-diamidino-2-phenylindole; IMT, intermitotic time. 


\section{INTRODUCTION}

A distinctive feature of the protist Pbysarum polycephalum is the developmental transition that links the two vegetative phases in the life cycle: uninucleate amoebae and multinucleate syncytial plasmodia. This transition involves many changes in cellular organization and gene expression (Bailey et al., 1987; Sweeney et al., 1987; Solnica-Krezel et al., 1988). Genetic analysis of wild-type isolates of $P$. polycephalum revealed that plasmodium formation is a sexual process and identified three naturally polymorphic loci that are involved in its control: $m a t B$ and $m a t C$, which influence the frequency of fusion between haploid amoebae; and mat $A$, which controls development of mat $A$ heteroallelic fusion cells into diploid plasmodia (Dee, 1987; Kawano et al., 1987).

Mutant isolation and classical genetic analysis were used to identify further genes involved in plasmodium formation in $P$. polycephalum. The value of such an approach in elucidating the number and possible roles of genes involved in a developmental process has been amply demonstrated by work in other systems (e.g. NussleinVolhard \& Wieschaus, 1980; Mullins \& NussleinVolhard, 1993). This approach is particularly effective in identifying genes whose functions are initially unknown. The $\operatorname{gad} A$ locus in $P$. polycephalum was identified by the isolation of mutant strains in which individual amoebae developed into haploid plasmodia without amoebal fusion (apogamic development; Bailey et al., 1987; Anderson et al., 1989). Phenotypic analysis showed that, apart from the absence of amoebal fusion, events in apogamic development are apparently identical to those in sexual development (Bailey et al., 1987, 1990). Genetic analysis indicated that the $\operatorname{gad} A$ mutations are inseparably linked to the mat $A$ locus but do not change the mat $A$ specificity exhibited by the wild-type amoebal strains from which they were isolated. Thus, the $\operatorname{mat} A \operatorname{gad} A$ genetic region apparently codes for more than one function related to the initiation of development. Unlike sexual strains, apogamic $(\operatorname{gad} A)$ mutant strains are temperature sensitive for development, with a permissive temperature of $21-22^{\circ} \mathrm{C}$. At the restrictive temperature $\left(29-30^{\circ} \mathrm{C}\right)$, apogamic mutants can be cultured as amoebae and mated with compatible sexual strains to form normal diploid plasmodia.

Apogamic strains provide a convenient haploid system for the isolation of mutants blocked in development. Using apogamic amoebae, Anderson \& Dee (1977) and others enriched for mutants unable to form plasmodia by replating cells cultured at the permissive temperature for development. Although almost 200 independent mutants were isolated by this method, genetic analysis showed that the majority fall into two complementation groups $(n p f B$ and $n p f C$ ), both closely linked to $\operatorname{mat} A$ and $\operatorname{gad} A$ (Anderson \& Dee, 1977; Davidow \& Holt, 1977; Honey et al., 1979, 1982; Anderson \& Holt, 1981; Anderson et al., 1989). Phenotypic analyses suggest that amoebae carrying the $n p f B$ and $n p f C$ mutations fail to initiate development and remain able to proliferate as amoebae (Anderson \& Dee, 1977; R. W. Anderson, unpublished observations). These observations provide further evidence that the mat $A$ genetic region encodes several functions related to the initiation of development. The enrichment method clearly favoured the isolation of $n p f B$ and $n p f C$ mutants and identified few other genes involved in plasmodium formation. To avoid the bias introduced by the enrichment method and to identify more genes required for development, we used the 'brute force' method developed by Wheals (1973), in which colonies formed by mutagenized apogamic amoebae were visually screened for those that failed to give normal plasmodia. The present paper reports genetic and phenotypic analysis of several $n p f$ mutants obtained in this screen, and of two mat $A$-unlinked mutations which were isolated using the enrichment method (Anderson \& Dee, 1977; Anderson et al., 1989).

To investigate the wild-type functions of the $n p f$ genes, we compared development in the mutants with development in apogamic ( $\left.\operatorname{gad} A n p f^{+}\right)$strains. Our previous cinematographic analysis of apogamic development showed that, following an apparently normal amoebal division, one or both daughter cells enter an extended cell cycle (Bailey et al., 1987, 1992a). During this cycle, the cell continues to grow in size for a period about two and a half times as long as a normal amoebal cell cycle, before becoming binucleate by mitosis without cytokinesis. During the second half of the long cell cycle, the cell acquires plasmodial characteristics such as ability to ingest amoebae and to fuse with genetically identical plasmodia (Bailey et al., 1987, 1992a). Other approaches showed that about halfway through the extended cell cycle, the developing haploid, uninucleate cell becomes committed to development and loses the ability to undergo the amoeba-flagellate transformation. Many changes in cellular organization also begin during this cell cycle; for example, extensive alterations in the microtubule cytoskeleton are initiated and plasmodium-specific tubulin isotypes become detectable (Solnica-Krezel et al., 1988, 1990, 1991).

Using the results of the above analyses of apogamic development, we determined the stage at which development became abnormal in the mutants and thus gained information about the times of action of the wildtype genes. By analysing the sequence of developmental events in the mutants we investigated the extent to which these events were dependent on one another. We used similar phenotypic analyses of double mutant strains to provide information on the interactions between different genes.

\section{METHODS}

Media. The following were used: LIA (liver infusion agar); SDM (semi-defined medium); DSDM agar (agar containing $6.25 \%, \mathrm{v} / \mathrm{v}, \mathrm{SDM}$; Blindt et al., 1986); DBL (5\%, w/v, liver infusion made from Difco Bacto Liver); DBL agar (agar containing DBL; Burland et al., 1984); SM-2 agar (Kawano $e t$ al., 1987); CB (concentrated live E. coli; Kawano et al., 1987); SBS (E. coli suspension in water; Burland et al., 1981); FKB (formalin-killed E. coli suspension; Dee, 1986). 
Table 1. Strains of $P$. polycephalum

\begin{tabular}{|c|c|c|}
\hline Strain & Relevant genotype & Reference \\
\hline $\mathrm{CH} 818$ & mat $A 2$ gad $A b$ matB2 matC1 fus $A 1$ fusC1 npfF1 & Anderson (1979) \\
\hline $\mathrm{CL}$ & $\operatorname{mat} A 2$ gad $A b \operatorname{matB} 1$ matC1 fus $A 2$ fus $C 1$ & Cooke \& Dee (1974) \\
\hline CL6111 & mat $A 2$ gad $A b$ matB1 matC1 fus $A 2$ fusC1 npf $A 1$ & Anderson \& Dee (1977) \\
\hline LU911 & mat $A 3$ gad $A^{+}$matB3 matC1 fus $A 2$ fusC1 whi $A 1$ & Anderson et al. (1989) \\
\hline RA267 & $\operatorname{mat} A 3 \mathrm{gad} A^{+}$mat $\mathrm{B} 2$ matC1 fus $A 1$ fus $C 1$ & Kawano et al. (1987) \\
\hline RA376 & $\operatorname{mat} A 3 \operatorname{gad} A 111 \operatorname{mat} B 3 \operatorname{mat} C 2$ fus $A 2$ fus $C 2$ & Anderson et al. (1989) \\
\hline RA422 & mat $A 3$ gad $A 111$ matB3 matC2 fus $A 2$ fus $C 2 n p f G 1$ & Anderson et al. (1989) \\
\hline RA545 & mat $A 3$ gad $A 111$ matB2 fus $A 2$ fusC1 npfF1 npfG1 & \\
\hline RA612 & $\operatorname{mat} A 2$ gad $A b$ matB1 matC1 fus $A 2$ fusC1 npfK1 & \\
\hline RA613 & $\operatorname{mat} A 2 \operatorname{gad} A b \operatorname{mat} B 1 \operatorname{mat} C 1$ fus $A 2$ fusC1 npfM1 & This study \\
\hline RA615 & $\operatorname{mat} A 3 \mathrm{gad} A 111$ matB3 matC2 fus $A 2$ fusC2 npfG2 & Ans stuay \\
\hline RA739 & $\operatorname{mat} A 2 \operatorname{gad} A b \operatorname{mat} B 1$ matC1 fus $A 2$ fusC1 npfF 2 & \\
\hline RA775 & mat $A 3$ gad A111 matB1 matC1 npfK1 npfL1 & \\
\hline
\end{tabular}

Strains. These are listed in Table 1.

Assays for growth and development. Amoebae were maintained in culture on DBL agar with SBS at $29-30^{\circ} \mathrm{C}$. This temperature inhibits apogamic plasmodium formation in strains carrying gad $A$ b or gad $A 111$. To test whether development could be initiated in the $n p f$ mutants, amoebae were inoculated at high density $\left(5 \times 10^{5}\right.$ per plate) with SBS on $9 \mathrm{~cm} \mathrm{DSDM}$ agar plates and incubated at $22{ }^{\circ} \mathrm{C}$ (Solnica-Krezel et al., 1988); this temperature permitted apogamic plasmodium formation to occur in gad $A b$ or gad $A 111$ strains with partial synchrony. At various times after inoculation, the cells were washed off a culture and $10^{2}-10^{4}$ cells were inoculated on DBL agar with SBS. After $4-5 \mathrm{~d}$ incubation at $30^{\circ} \mathrm{C}$, the number of amoebal colonies was counted. Efficiency of replating (\%) was calculated as:

(mean no. of colonies per plate/no. of cells plated) $\times 100$.

For the experiments shown in Figs 1 and 3, $6 \times 10^{4}$ amoebae were spread with $C B$ over an area of approximately $5 \mathrm{~cm}^{2}$ on SM-2 agar. At various times after inoculation, cell proliferation was measured by washing the cells off a sample of plates and the estimating total number of cells per culture using a haemocytometer.

Isolation of npf mutants. Mutagenesis and subsequent isolation of mutant strains from CL or RA376 were performed as described in Bailey et al. (1992a). All the npf mutants were originally isolated in strains carrying a gad $A$ mutation which was dominant to the wild-type $\mathrm{gad}^{+}$allele.

\section{Genetic analysis of npf mutants}

Tests of dominance. To determine whether the mutation carried by each $n p f$ strain was dominant or recessive to the corresponding $n p f^{+}$allele, crossing tests were set up on SM-2 agar at $21{ }^{\circ} \mathrm{C}$ as described by Anderson et al. (1989). In these tests, amoebae of each mutant were mixed with an $n p f^{+}$strain carrying the same mat $A$ allele but different alleles of the mat $B$ and $f u s A$ loci, which affect amoebal and plasmodial fusion respectively. These mixtures may be represented as

$n p f \operatorname{gad} A$ mat $A x \operatorname{mat} B y$ fus $A m$

$$
\times n p f^{+} \operatorname{gad} A^{+} \operatorname{mat} A \times \operatorname{mat} B z \text { fus } A n
$$

The presence of unlike mat $B$ alleles ensured that amoebal fusions occurred with high frequency. Although heteroallelism for mat $A$ is normally essential if fusion cells are to develop into plasmodia, mat $A$-homoallelic mixtures were used for these tests so that plasmodium formation would be dependent upon the dominant gad $A$ mutation carried by each mutant. The fusion cells formed in each mixture would develop into plasmodia unless development was blocked by the $n p f$ mutation. Thus the formation of crossed plasmodia in a mixture was evidence that the $n p f$ mutation was recessive to $n p f^{+}$. The $f u s A$ gene controls somatic fusions between plasmodia, and was used to confirm that plasmodia arising in the mixtures were formed by crossing rather than apogamy; only crossed plasmodia would fuse with a tester plasmodium that was heterozygous for $f u s A$ alleles (for details see Anderson \& Dee, 1977).

Tests of segregation. Amoebae of each mutant strain were crossed with one or more $n p f^{+}$strains, and the segregation of the mutant phenotype was studied in meiotic progeny. Methods were as described by Anderson et al. (1989). For mutants carrying a single $n p f$ mutation, each cross may be represented as

$$
n p f \operatorname{gad} A \times n p f^{+} \operatorname{gad} A^{+}
$$

Among haploid meiotic progeny of such a cross, it was expected that only recombinants of the genotype $n p f^{+}$gad $A$ would be able to form plasmodia apogamically. If the $n p f$ and gad loci were unlinked, the expected frequency of such recombinants would be $25 \%$. Amoebal progeny clones derived from each cross were therefore tested for their ability to develop apogamically at $21^{\circ} \mathrm{C}$ in 'selfing spot tests' (Anderson et al., 1989). Progeny that failed to develop apogamically were classified for $n p f$ and $\operatorname{gad} A$ alleles in further crossing tests. The details of these additional tests differed for each mutation, but all analyses were similar in principle to that reported by Bailey et al. (1992a) for the mutant strain RA614. For example, progeny of the cross RA422 $\times$ RA267 ( $\left.n p f G 1 \operatorname{gad} A 111 \operatorname{mat} A 3 \times n p f G^{+} \operatorname{gad} A^{+} \operatorname{mat} A 3\right)$ were analysed as follows (see Table 5). Progeny that formed plasmodia in clonal cultures at $21{ }^{\circ} \mathrm{C}$ were identified as $n p f G^{+}$ gad $A 111$ recombinants. The remaining clones were mixed with an $n p f G^{+}$gad $A^{+}$mat $A 3$ tester strain and incubated at $21^{\circ} \mathrm{C}$. These mixtures were all heteroallelic for mat $B$ to ensure that amoebal fusion would occur with high frequency. Since the progeny and tester strains carried the same mat $A$ allele, crossing in the mixtures could occur only if the progeny strain carried the gad $A 111$ allele from RA422; such progeny would have developed apogamically in the clonal tests, however, unless they also carried the $n p f G 1$ mutation from RA422. Of the $n p f G 1$ gad $A 111$ mat $A 3$ progeny that were identified in this way, several were used as tester strains in further mat $B$-heteroallelic mixtures 
to determine the $n p f G$ allele carried by each $g a d^{+}$progeny strain; those carrying the $n p f G 1$ mutation were identified by their failure to cross with the $n p f G 1$ tester.

Complementation of npf mutants. Complementation tests were carried out by setting up crossing tests (Anderson et al., 1989) in which amoebae of two $n p f$ mutant strains were mixed together. The absence of crossed plasmodia indicated that the mutants did not complement. To ensure that amoebal fusion would occur with high frequency in these mixtures, strains carrying unlike mat $B$ alleles were used. The mixtures were also heteroallelic for the plasmodial fusion locus $f u s A$ so that hybrid plasmodia could be positively identified as described above.

Recombination of npf mutations. Meiotic progeny of crosses between different mutants were tested to determine whether pairs of $n p f$ mutations recombined freely (Anderson et al., 1989). These analyses differed in detail according to the mutations involved, but are exemplified by the analysis of progeny from the cross $\mathrm{RA} 422 \times \mathrm{CH} 818\left(n p f F^{+} n p f G 1 \operatorname{gad} A 111 \operatorname{mat} A 3 \times\right.$ $n p f F 1 n p f G^{+} \operatorname{gad} A b$ mat $A 2$; see Table 6). Progeny were first classified for mat $A$ alleles by incubating them in crossing tests (Anderson et al., 1989) with mat $A 2$ and mat $A 3$ tester strains. These tests were incubated at $29^{\circ} \mathrm{C}$, a temperature that abolished expression of the gad $A 111$ mutation, and greatly inhibited expression of gad $A b$, but permitted extensive crossing between strains carrying different mat $A$ alleles. Progeny were assigned the mat $A$ allele of the tester strain with which they failed to form crossed plasmodia. Since mat $A$ and gad $A$ are inseparable in meiotic crosses, progeny classified as mat $A 2$ could also be identified as those carrying gad $A b$, and mat $A 3$ progeny could be identified as those carrying gad $A 111$. Among the gad $A 111$ progeny, those that formed plasmodia in clonal cultures at $21^{\circ} \mathrm{C}$ were classified as $n p f \mathrm{~F}^{+} n p f G^{+}$recombinants. The remaining gad $A 111$ progeny were classified for $n p f$ alleles by testing their ability to cross with $n p f F 1$ and $n p f G 1$ tester strains (see Table 6). Since apogamic development in gad $A b$ strains was not completely abolished at $29^{\circ} \mathrm{C}$, progeny of the genotype $n p f \mathrm{~F}^{+} n p f G^{+}$ gad $A b$ were identified by the formation of plasmodia in clonal cultures at both $21^{\circ} \mathrm{C}$ and $29^{\circ} \mathrm{C}$. The remaining gad $A b$ progeny were classified for $n p f$ alleles by testing their ability to cross with $n p f \mathrm{~F} 1$ and $n p f G 1$ tester strains (see Table 6).

Time-lapse cinematography. Filming was carried out in cavity slides using an initial cell density of $4 \times 10^{5}$ cells $\mathrm{ml}^{-1}$, and the equipment and conditions described by Bailey et al. (1987). Filming was started 2 or $3 \mathrm{~d}$ after inoculation, at which time the cells had excysted and divided to give small colonies. Filming continued for $66 \mathrm{~h}$. One frame was exposed every $30 \mathrm{~s}$ with an exposure time of $0.2 \mathrm{~s}$. Intermitotic time (IMT) was measured from nucleolar disappearance in one cell cycle to nucleolar disappearance in the next cell cycle. Cell area was measured as described by Bailey et al. (1987). Each arbitrary unit of area represents $7 \cdot 30 \mu \mathrm{m}^{2}$ in the slide culture but area measurements from different films cannot be compared directly because of variation between slides in the amount of cell flattening.

Immunofluorescence microscopy. The 6-11B-1 antibody against acetylated $\alpha$-tubulin was kindly provided by $\mathrm{Dr}$ G. Piperno (The Rockefeller University, New York, USA; Piperno \& Fuller, 1985). KMX-1 recognizes all $\beta$-tubulin isotypes (Birkett et al., 1985) and KMP-1 is specific for the Physarum $\alpha 3$-tubulin isotype (Walden et al., 1989). The $\beta 2$ tubulin antibody specifically recognizes the Physarum $\beta 2$-tubulin isotype (Diggins-Gilicinski et al., 1989). Fluorescently labelled secondary antibodies were obtained from Jackson ImmunoResearch Laboratories. Cells were fixed, stained with antibodies and DAPI (4',6-diamidino-2-phenylindole), and mounted as described by Diggins-Gilicinski et al. (1989), with modifications for the 6-11B-1 antibody described by Solnica-Krezel et al. (1990). Cells were examined using a Zeiss Axiophot microscope.

\section{RESULTS AND DISCUSSION}

Genetic analysis was carried out on all the $n p f$ mutants (see Methods). For tests of dominance, fusion cells were constructed that were heteroallelic for $\operatorname{gad} A$ and homoallelic for mat $A$. In wild-type strains, sexual development occurs only in fusion cells that are heteroallelic for $\operatorname{mat} A$; thus, the mat $A$-homoallelic cells developed into plasmodia only because the $\operatorname{gad} A$ mutation was dominant. If plasmodia developed in mat $A$-homoallelic crosses between gad $A n p f$ amoebae and wild-type $\left(\mathrm{gad}^{+} n p f^{+}\right)$amoebae, we concluded that the $n p f$ mutation was recessive. Recessive $n p f$ mutants could then be tested for complementation by combining them with each other. To investigate linkage, mat $A$-heteroallelic crosses were set up between $n p f$ mutants and strains carrying other genetic markers. Heterozygous plasmodia were allowed to sporulate and samples of amoebal progeny clones from spores were analysed. All the $n p f$ mutations were isolated from $\operatorname{gad} A$ strains and so by definition interfered with apogamic development, but it was also of interest to test their effects on sexual development. For this purpose, crosses were set up between strains that carried the same $n p f$ mutation but different alleles of mat $A$ and matB. If the $n p f$ mutation affected sexual development, no wild-type plasmodia were expected.

Occasionally some apparently normal macroplasmodia were obtained from clones of amoebae carrying an $n p f$ mutation. We obtained spores from such plasmodia and tested the phenotype of the progeny. If the progeny were non-mutant, we assumed that reversion of the mutation had occurred. If the progeny of the plasmodium were themselves mutant, then we assumed that the original plasmodium had arisen in some other way than by reversion; such mutations were defined as 'leaky'.

For phenotypic characterization of the $n p f$ mutants, we cultured the amoebae in conditions permissive for plasmodium development and looked for cellular markers known to be associated with development in wild-type strains (Bailey et al., 1987, 1992a). If any cells of a mutant strain exhibited one or more of these developmental markers, we concluded that development had been initiated. The markers also enabled us to determine the stage at which plasmodium development first became abnormal, whether there was a characteristic sequence of events after this time, and the terminal phenotype of each mutant. The $n p f$ mutants were isolated from different $\operatorname{gad} A$ mutants ( $g a d A b$ and gad $A 111$ ) with slightly different characteristics, and this had to be borne in mind when analysing their phenotypes.

\section{Time-lapse cinematography}

As in our previous studies of normal development (Bailey et al., 1987, 1990, 1992a), we used time-lapse cinematography to analyse the growth and development of individual cells over extended periods. Using this technique, we monitored cell cycle lengths, cell growth, 
Table 2. Expression of tubulin isotypes in npf mutants

\begin{tabular}{|c|c|c|c|c|c|c|}
\hline \multirow[t]{2}{*}{ Mutant } & \multirow{2}{*}{$\begin{array}{c}\text { Culture } \\
\text { no. }\end{array}$} & \multirow{2}{*}{$\begin{array}{c}\text { Days of } \\
\text { development }\end{array}$} & \multicolumn{2}{|c|}{ Presence of $\beta 2$-tubulin } & \multicolumn{2}{|c|}{ Absence of $\alpha 3$-tubulin } \\
\hline & & & $\begin{array}{l}\text { No. of cells } \\
\text { scored }\end{array}$ & $\begin{array}{c}\% \beta 2- \\
\text { positive }\end{array}$ & $\begin{array}{l}\text { No. of cells } \\
\text { scored }\end{array}$ & $\begin{array}{c}\% \propto 3- \\
\text { negative }\end{array}$ \\
\hline \multirow[t]{3}{*}{$n p f A 1$} & 1 & 3 & 1000 & 0 & 550 & $0 \cdot 5$ \\
\hline & 2 & 3 & 1200 & $0 \cdot 1$ & 530 & 0.8 \\
\hline & 3 & 4 & 1030 & $0 \cdot 7$ & 500 & $0 \cdot 0$ \\
\hline \multirow[t]{3}{*}{$n p f F 1$} & 1 & 3 & 880 & $0 \cdot 0$ & 300 & $0 \cdot 2$ \\
\hline & 2 & 3 & 1000 & 34.9 & 1000 & $26 \cdot 2$ \\
\hline & 3 & 7 & 1040 & $6 \cdot 7$ & 400 & $19 \cdot 6$ \\
\hline \multirow[t]{3}{*}{$n p f G 1$} & 1 & 3 & 1000 & $0 \cdot 1$ & 1000 & $0 \cdot 2$ \\
\hline & 2 & 3 & 1100 & 0 & 1000 & $0 \cdot 7$ \\
\hline & 3 & 5 & 1000 & 0 & 1000 & $0 \cdot 5$ \\
\hline \multirow[t]{3}{*}{$n p f G 2$} & 1 & 3 & 1100 & 0 & 1000 & $0 \cdot 2$ \\
\hline & 2 & 5 & 1000 & 0 & 1000 & $0 \cdot 1$ \\
\hline & 3 & 7 & 1000 & 0 & 250 & 4 \\
\hline \multirow[t]{2}{*}{$n p f K 1$} & 1 & 3 & 400 & $31 \cdot 8$ & - & - \\
\hline & 2 & 4 & - & - & - & - \\
\hline \multirow[t]{3}{*}{$n p f M 1$} & 1 & 3 & 550 & $51 \cdot 2$ & 500 & $10 \cdot 0$ \\
\hline & 2 & 4 & 530 & $54 \cdot 7$ & 530 & $13 \cdot 4$ \\
\hline & 3 & 5 & 790 & $55 \cdot 1$ & 340 & $32 \cdot 0$ \\
\hline$n p f F 1 /$ & 1 & 3 & 1260 & 0 & 1060 & 0.6 \\
\hline \multirow[t]{2}{*}{$n p f G 1$} & 2 & 3 & 1040 & 0 & 1050 & 0 \\
\hline & 3 & 5 & 1150 & 0 & 1040 & 0.5 \\
\hline$n p f K 1 /$ & 1 & 3 & 540 & $17 \cdot 7$ & 620 & $6 \cdot 3$ \\
\hline \multirow[t]{3}{*}{$n p f L 1$} & 2 & 3 & 530 & $25 \cdot 9$ & 520 & $15 \cdot 0$ \\
\hline & 3 & 4 & 400 & $34 \cdot 3$ & 260 & $26 \cdot 1$ \\
\hline & 4 & 4 & 530 & $43 \cdot 2$ & 340 & $41 \cdot 2$ \\
\hline
\end{tabular}

morphology, behaviour, and progression to the terminal phenotypes of the mutants.

\section{Assays of cell growth and differentiation}

Commitment to plasmodium formation. When cells from developing apogamic cultures are replated at low density, cells that are committed to development at the time of replating can be assayed because they fail to proliferate as amoebae and instead grow into plasmodia (Youngman $e t$ al., 1977). To test whether committed cells formed in cultures of a developmental mutant but failed to grow into plasmodia when replated, we estimated the proportion of cells in the suspension that failed to form amoebal colonies when replated (i.e. efficiency of replating).

Cell proliferation. Cultures of apogamic amoebae characteristically have lower rates of cell proliferation at $21^{\circ} \mathrm{C}$ than heterothallic gad $A^{+}$amoebae at the same temperature, because cells in the apogamic culture that have initiated development no longer divide; at the nonpermissive temperature for development $\left(30^{\circ} \mathrm{C}\right)$, both types of amoebae grow at the same rate. Measurements of the relative rates of cell proliferation at the two temperatures were therefore used as tests for the formation of committed cells in the mutant strains.
Flagellate formation. Cells in developing apogamic cultures lose the ability to undergo the amoeba-flagellate transformation at about the same time as they become committed. We used the method of Blindt et al. (1986) to estimate the proportion of cells able to undergo this transformation at various times during growth of a culture.

\section{Assays based on fluorescence microscopy}

Tubulin gene expression. The $\alpha 3$-tubulin isotype is detectable in amoebae but not in plasmodia (Diggins \& Dove, 1987; Sasse et al., 1987); in most cells, $\alpha 3$-tubulin staining becomes undetectable during the extended cell cycle (Solnica-Krezel et al., 1990). In contrast, the plasmodium-specific $\beta 2$-tubulin isotype is first detected in developing cultures shortly after the first committed cells are detected (Burland et al., 1988; Solnica-Krezel et al., 1988, 1990; Diggins-Gilicinski et al., 1989). We examined individual cells for the presence or absence of the $\alpha 3$ - and $\beta 2$-tubulin isotypes.

Spindle types. Using the definitions of spindle types given below, we determined the frequency of each spindle type in mitotic uninucleate cells stained with tubulin antibodies. (i) Amoebal spindles were bipolar and had asters 
Table 3. Cell types in cultures of npf mutants

\begin{tabular}{|c|c|c|c|c|c|c|c|c|}
\hline \multirow[t]{2}{*}{ Mutant } & \multirow{2}{*}{$\begin{array}{c}\text { Culture } \\
\text { no. }\end{array}$} & \multirow{2}{*}{$\begin{array}{c}\text { Days of } \\
\text { development }\end{array}$} & \multirow{2}{*}{$\begin{array}{l}\text { No. of cells } \\
\text { scored }\end{array}$} & \multicolumn{5}{|c|}{ Percentage of cell type in culture } \\
\hline & & & & Uninucleate & Ingesting & Binucleate & Quadrinucleate & Multinucleate \\
\hline \multirow[t]{3}{*}{$n p f A 1$} & 1 & 3 & 1000 & 100 & 0 & 0 & 0 & 0 \\
\hline & 2 & 3 & 2000 & 100 & 0 & 0 & 0 & 0 \\
\hline & 3 & 4 & 110 & 100 & 0 & 0 & 0 & 0 \\
\hline \multirow[t]{3}{*}{$n p f F 1$} & 1 & 3 & - & - & - & - & - & - \\
\hline & 2 & 3 & 1040 & $99 \cdot 8$ & 0 & $0 \cdot 2$ & 0 & 0 \\
\hline & 3 & 7 & 500 & $99 \cdot 2$ & 0 & 0.8 & 0 & 0 \\
\hline \multirow{3}{*}{$n p f G 1$} & 1 & 3 & 1025 & 100 & 0 & 0 & 0 & 0 \\
\hline & 2 & 3 & 1090 & 99.8 & 0 & 0.2 & 0 & 0 \\
\hline & 3 & 5 & 1070 & 100 & 0 & 0 & 0 & 0 \\
\hline \multirow[t]{3}{*}{$n p f G 2$} & 1 & 3 & 1100 & 100 & 0 & 0 & 0 & 0 \\
\hline & 2 & 5 & 1090 & 100 & 0 & 0 & 0 & 0 \\
\hline & 3 & 7 & 500 & 100 & 0 & 0 & 0 & 0 \\
\hline \multirow[t]{2}{*}{$n p f K 1$} & 1 & 3 & 280 & $95 \cdot 4$ & - & - & - & $4 \cdot 6$ \\
\hline & 2 & 4 & 480 & - & - & - & - & $42 \cdot 3$ \\
\hline \multirow{3}{*}{$n p f M 1$} & 1 & 3 & 1200 & $84 \cdot 4$ & $1 \cdot 4$ & $12 \cdot 8$ & 0.6 & 0 \\
\hline & 2 & 4 & 580 & 78.5 & $1 \cdot 0$ & 17.5 & 1.7 & $1 \cdot 2$ \\
\hline & 3 & 5 & 1000 & $78 \cdot 1$ & $1 \cdot 0$ & $18 \cdot 5$ & $2 \cdot 0$ & 0.4 \\
\hline$n p f F 1 /$ & 1 & 3 & 1200 & 100 & 0 & 0 & 0 & 0 \\
\hline \multirow{2}{*}{$n p f G 1$} & 2 & 3 & 1040 & $99 \cdot 9$ & 0 & $0 \cdot 1$ & 0 & 0 \\
\hline & 3 & 5 & 1050 & 100 & 0 & 0 & 0 & 0 \\
\hline$n p f K 1 /$ & 1 & 3 & 640 & $94 \cdot 5$ & $2 \cdot 2$ & $2 \cdot 4$ & 0.9 & 0 \\
\hline \multirow[t]{3}{*}{$n p f \mathrm{~L} 1$} & 2 & 3 & 600 & $88 \cdot 9$ & 0.7 & $9 \cdot 4$ & 0.8 & $0 \cdot 2$ \\
\hline & 3 & 4 & 540 & $89 \cdot 0$ & 0.9 & 7.9 & $1 \cdot 7$ & 0.6 \\
\hline & 4 & 4 & 580 & $87 \cdot 3$ & 0.5 & $10 \cdot 1$ & $1 \cdot 4$ & 0.7 \\
\hline
\end{tabular}

and $\alpha 3$-tubulin staining at the poles (Havercroft \& Gull, 1983; Solnica-Krezel et al., 1991). (ii) Plasmodial spindles were bipolar, did not have asters or $\alpha 3$-tubulin staining at the poles, but usually had one or two additional cytoplasmic microtubule-organizing centres (MTOC) that often stained for $\alpha 3$-tubulin (Havercroft \& Gull, 1983; Solnica-Krezel et al., 1991). (iii) Other bipolar spindles that could not definitely be classed as either amoebal or plasmodial were classified as unidentified (Bailey et al., 1992a). At the end of the extended cell cycle, most developing uninucleate cells undergo plasmodial mitosis, although some cells from other types of spindle (SolnicaKrezel et al., 1991; Bailey et al., 1992a); all subsequent mitoses are of the plasmodial type (Solnica-Krezel $e t$ al., 1991). (iv) In star microtubular arrays, the microtubules radiated in the form of a star and the condensed chromosomes formed a mass in the centre of the array; these spindles were usually associated with two $\alpha 3-$ tubulin-containing structures (Solnica-Krezel et al., 1991). (v) In uninucleate mitotic cells with multipolar spindles, there were more than two astral spindle poles and several chromatin masses (Bailey et al., 1992a). Star microtubular arrays and multipolar spindles with more than three poles have been observed only in cultures containing developing cells. These spindle types were therefore regarded as markers of development even though it was assumed that they do not allow correct chromosome separation and result in inviable cells.

Nuclear morphology. Using DAPI staining, we looked for cells with condensed nuclei in cultures of $n p f$ mutants. Condensed nuclei were observed at high frequency in cultures of a previously studied $n p f$ mutant ( $n p f \mathrm{~L} 1$, Bailey et al., 1992a) and at low frequency in cultures of the gad $A 111 n p f \mathrm{~L}^{+}$parental strain at temperatures permissive for development. Such nuclei are not a specific consequence of the $n p f L 1$ mutation, but appear to be due to apoptosis-like cell death. Apoptosis occurs only in cells that have begun development and has never been observed in vegetative amoebae.

Cell morphology. Using DAPI staining, we determined the proportions of binucleate cells and cells that had ingested amoebae in cultures of $n p f$ mutants.

\section{Mutations causing early blocks in plasmodium development}

npfA. The mutant strain CL6111 carries the recessive $n p f A 1$ mutation; this strain was isolated from the gad $A b$ strain CL following mutagenesis of amoebae and enrichment for cells that failed to form plasmodia (Anderson $\&$ Dee, 1977). Numerous plasmodia of wild-type pheno- 
Table 4. Types of mitotic spindles formed in cultures of npf mutants

\begin{tabular}{|c|c|c|c|c|c|c|c|c|c|}
\hline \multirow[t]{2}{*}{ Mutant } & \multirow{2}{*}{$\begin{array}{c}\text { Culture } \\
\text { no. }\end{array}$} & \multirow{2}{*}{$\begin{array}{c}\text { Days of } \\
\text { development }\end{array}$} & \multirow{2}{*}{$\begin{array}{l}\text { No. of cells } \\
\text { assayed }\end{array}$} & \multicolumn{5}{|c|}{ Uninucleate spindles (\%) } & \multirow{2}{*}{$\begin{array}{l}\text { Multinucleate } \\
\text { spindles (\%) }\end{array}$} \\
\hline & & & & Amoebal & Plasmodial & Star & Multipolar & Unidentified & \\
\hline \multirow[t]{3}{*}{$n p f A 1$} & 1 & 3 & 541 & $93 \cdot 3$ & 0 & 0 & $0 \cdot 4$ & $6 \cdot 3$ & 0 \\
\hline & 2 & 3 & 1097 & $95 \cdot 5$ & 0 & 0 & $1 \cdot 2$ & 3.9 & 0 \\
\hline & 3 & 4 & 367 & $95 \cdot 6$ & 0 & 0 & $0 \cdot 5$ & $3 \cdot 5$ & $0 \cdot 3$ \\
\hline \multirow[t]{3}{*}{$n p f F 1$} & 1 & 3 & 91 & 88 & 0 & 0 & 0 & 12 & 0 \\
\hline & 2 & 3 & 767 & $46 \cdot 9$ & 6.8 & $20 \cdot 7$ & $6 \cdot 1$ & $18 \cdot 0$ & $0 \cdot 1$ \\
\hline & 3 & 7 & 581 & $71 \cdot 1$ & $1 \cdot 5$ & $10 \cdot 7$ & $6 \cdot 5$ & $10 \cdot 0$ & 0 \\
\hline \multirow[t]{3}{*}{$n p f G 1$} & 1 & 3 & 1051 & $92 \cdot 9$ & 0 & 0 & $0 \cdot 4$ & 6.7 & 0 \\
\hline & 2 & 3 & 1045 & $86 \cdot 1$ & 0 & $0 \cdot 1$ & $0 \cdot 1$ & $13 \cdot 7$ & 0 \\
\hline & 3 & 5 & 1059 & $94 \cdot 4$ & 0 & 0.6 & $0 \cdot 3$ & $4 \cdot 7$ & 0 \\
\hline \multirow[t]{3}{*}{$n p f G 2$} & 1 & 3 & 1128 & $87 \cdot 3$ & 0 & $0 \cdot 1$ & $0 \cdot 1$ & $12 \cdot 5$ & 0 \\
\hline & 2 & 5 & 1197 & $81 \cdot 7$ & 0 & $10 \cdot 7$ & $0 \cdot 9$ & 6.6 & 0 \\
\hline & 3 & 7 & 346 & $70 \cdot 8$ & 0 & $15 \cdot 3$ & $2 \cdot 9$ & $11 \cdot 0$ & 0 \\
\hline \multirow[t]{2}{*}{$n p f K 1$} & 1 & 3 & 135 & $64 \cdot 1$ & 5.9 & $14 \cdot 1$ & 0 & $20 \cdot 0$ & $30 \cdot 0$ \\
\hline & 2 & 4 & 191 & $23 \cdot 6$ & $19 \cdot 4$ & 0 & 0 & $25 \cdot 0$ & $31 \cdot 4$ \\
\hline \multirow[t]{3}{*}{$n p f M 1$} & 1 & 3 & 589 & $57 \cdot 2$ & $16 \cdot 0$ & $2 \cdot 3$ & 1.5 & $21 \cdot 4$ & $1 \cdot 5$ \\
\hline & 2 & 4 & 326 & $47 \cdot 5$ & $24 \cdot 2$ & $4 \cdot 3$ & $0 \cdot 6$ & $22 \cdot 1$ & $1 \cdot 2$ \\
\hline & 3 & 5 & 257 & $50 \cdot 8$ & $19 \cdot 0$ & $5 \cdot 0$ & $4 \cdot 0$ & $17 \cdot 0$ & $5 \cdot 0$ \\
\hline \multirow{3}{*}{$\begin{array}{r}n p f G 1 / \\
n p f F 1\end{array}$} & 1 & 3 & 1053 & $90 \cdot 3$ & 0 & 0 & 0 & $9 \cdot 7$ & 0 \\
\hline & 2 & 3 & 1065 & $94 \cdot 0$ & 0 & $1 \cdot 1$ & $0 \cdot 4$ & 4.5 & $0 \cdot 1$ \\
\hline & 3 & 5 & 1189 & $94 \cdot 9$ & 0 & $0 \cdot 7$ & $0 \cdot 3$ & $4 \cdot 1$ & 0 \\
\hline \multirow{4}{*}{$\begin{array}{c}n p f K 1 / \\
n p f L 1\end{array}$} & 1 & 3 & 548 & $66 \cdot 2$ & $2 \cdot 9$ & $9 \cdot 7$ & $2 \cdot 2$ & $13 \cdot 1$ & $5 \cdot 8$ \\
\hline & 2 & 3 & 597 & $43 \cdot 9$ & 6.9 & $35 \cdot 5$ & $3 \cdot 7$ & $9 \cdot 9$ & $0 \cdot 2$ \\
\hline & 3 & 4 & 186 & $34 \cdot 9$ & $10 \cdot 6$ & $25 \cdot 4$ & $1 \cdot 1$ & $17 \cdot 5$ & $10 \cdot 6$ \\
\hline & 4 & 4 & 599 & $33 \cdot 7$ & $7 \cdot 8$ & $38 \cdot 4$ & $4 \cdot 0$ & $11 \cdot 7$ & $4 \cdot 3$ \\
\hline
\end{tabular}

type were formed at $29^{\circ} \mathrm{C}$ in crosses between $n p f A 1$ strains carrying different mat $A$ alleles, indicating that the $n p f A^{+}$allele was not essential for sexual development. The $n p f A$ locus is unlinked to the developmental loci $n p f F$, $n p f L$ and mat $A$ (Anderson \& Dee, 1977; Bailey et al., 1992a). Our analyses showed that $n p f A$ was also unlinked to $n p f G, n p f K$ and $n p f M$ (data not shown; $P>0 \cdot 05, \chi^{2}$ tests).

Anderson \& Dee (1977) reported that plasmodia consistently arose at low frequencies $\left(1\right.$ in $10^{5}$ cells) in cultures of $n p f A 1$ apogamic amoebae at $22^{\circ} \mathrm{C}$ but not at $28.5^{\circ} \mathrm{C}$, just below the restrictive temperature for apogamic development in CL. One plasmodium was induced to sporulate and the spores were allowed to germinate. None of the resulting amoebal colonies formed plasmodia at significantly higher frequency than CL6111, indicating that the plasmodium had not arisen by reversion but that the mutation was leaky.

In cultures of CL6111 at $22{ }^{\circ} \mathrm{C}$, the only evidence for development was the presence of a small proportion of $\beta 2$ tubulin positive cells after 3-4 d culture (Table 2). The proportions of cells showing other markers of development were not different from the levels seen in vegetative amoebal cultures (Tables 2-4). A few (0.4-
$1 \cdot 2 \%$; Table 4) abnormal, tripolar mitotic spindles were observed which had astral microtubules and equal distribution of the DNA between the poles; such tripolar spindles occur at a low level in all amoebal cultures and are not related to plasmodium development but rather to the occasional formation of diploid amoebae (Bailey et al., 1990).

Since the overwhelming majority of cells in $n p f A 1$ cultures did not show any of the developmental markers, we conclude that the product of the $n p f A^{+}$gene must be required at or close to the time at which development is initiated. Although few $\beta 2$-tubulin positive cells were detected, their frequency was higher than the frequency at which plasmodium formation occurred, indicating that most of them did not go on to form plasmodia. Since no binucleate cells were observed, most of the cells presumably died before undergoing a plasmodial mitosis.

npfG. The mutant strain RA422 was isolated from the gad A111 strain RA376 following enrichment by Anderson et al. (1989). Our analyses confirmed the results of Anderson et al. (1989) that RA422 carried a single nuclear gene mutation ( $n p f G 1)$ : segregation of $n p f G 1: n p f G^{+} \operatorname{did}$ not differ significantly from $1: 1$ among meiotic progeny of several crosses ( $P>0 \cdot 05, \chi^{2}$ tests), and alleles of $\operatorname{gad} A$ 
Table 5. Segregation of npfG alleles among progeny of the cross RA422 (npfG1 gadA111 matA3) $\times$ RA267 (npfG ${ }^{+}$gadA $A^{+}$matA3)

\begin{tabular}{|c|c|c|c|c|c|}
\hline \multicolumn{3}{|c|}{ Plasmodium formation at $21^{\circ} \mathrm{C}$ in } & \multirow{3}{*}{$\begin{array}{l}\text { No. of } \\
\text { progeny in } \\
\text { class }\end{array}$} & \multicolumn{2}{|c|}{ Deduced genotype of class } \\
\hline \multirow{2}{*}{$\begin{array}{l}\text { Clonal } \\
\text { cultures }\end{array}$} & \multicolumn{2}{|c|}{ Crosses of progeny with } & & & \\
\hline & $\begin{array}{c}n p f G^{+} \operatorname{gadA} A^{+} \\
\text {matA3 }\end{array}$ & $\begin{array}{l}n p f G 1 \operatorname{gad} A 111 \\
\text { mat } A 3\end{array}$ & & & \\
\hline+ & $\mathrm{ND}$ & ND & 5 & $n p f G^{+}$ & $\operatorname{gad} A 111$ \\
\hline - & + & - & 9 & $n p f G 1$ & $\operatorname{gad} A 111$ \\
\hline - & - & + & 9 & $n p f G^{+}$ & $\operatorname{gad} A^{+}$ \\
\hline \multirow[t]{2}{*}{-} & - & - & 7 & $n p f G 1$ & $\operatorname{gad} A^{+}$ \\
\hline & & & 30 & & \\
\hline
\end{tabular}

Key: + , plasmodia formed; -, no plasmodia formed; ND, not done.

Table 6. Analysis of progeny from the cross RA422 (npfG1 $n p f F^{+}$gadA111 matA3) $\times$ CH818 (npfF1 npfG ${ }^{+}$gadAh matA2)

\begin{tabular}{|c|c|c|c|c|c|c|c|c|}
\hline \multicolumn{2}{|c|}{$\begin{array}{l}\text { Crossing at } \\
29^{\circ} \mathrm{C} \text { with }\end{array}$} & \multicolumn{2}{|c|}{$\begin{array}{c}\text { Plasmodium } \\
\text { formation in } \\
\text { clonal } \\
\text { cultures at }\end{array}$} & \multicolumn{2}{|c|}{ Crossing with } & \multirow[t]{2}{*}{$\begin{array}{l}\text { No. in } \\
\text { class }\end{array}$} & \multicolumn{2}{|c|}{ Genotype of class } \\
\hline mat $A 2$ & mat $A 3$ & $21^{\circ} \mathrm{C}$ & $29^{\circ} \mathrm{C}$ & $n p f F 1^{*}$ & $n p f G 1 \dagger$ & & & \\
\hline \multirow{5}{*}{+} & & + & - & ND & ND & 4 & $n p f F^{+} n p f G^{+}$ & \\
\hline & - & - & - & - & + & 3 & $n p f F 1 n p f G^{+}$ & $\operatorname{mat} A 3 \operatorname{gad} A 111$ \\
\hline & & - & - & + & - & 7 & $n p f F^{+} n p f G 1$ & \\
\hline & & - & - & - & - & 7 & $n p f \mathrm{~F} 1 n p f G 1$ & \\
\hline & & + & + & ND & ND & 8 & $n p f \mathrm{~F}^{+} n p f G^{+}$ & \\
\hline \multirow[t]{4}{*}{-} & + & - & - & - & + & 7 & $n p F 1 n p f G^{+}$ & $\operatorname{mat} A 2 \operatorname{gad} A b$ \\
\hline & & $+\ddagger$ & - & + & - & 7 & $n p f F^{+} n p f G 1$ & \\
\hline & & - & - & - & - & 4 & $n p f F 1 n p f G 1$ & \\
\hline & & & & & & 47 & & \\
\hline
\end{tabular}

Key: +, plasmodia formed; -, no plasmodia formed; ND, not done.

* mat $A$-heteroallelic mixtures at $29^{\circ} \mathrm{C}$.

† mat $A$-homoallelic mixtures at $21^{\circ} \mathrm{C}$ for gad $A 111$ progeny or $29^{\circ} \mathrm{C}$ for gad $A b$ progeny.

$\ddagger$ At $21^{\circ} \mathrm{C} n p f G 1$ strains carrying gad $A b$ form a few plasmodia.

and $n p f G$ recombined freely (Table 5 shows an analysis of progeny from one cross; see Methods for details). One of the new mutants, RA615, isolated by the brute force method from RA376, failed to complement tester strains carrying $n p f G 1$, and it was concluded that this strain carried a second $n p f G$ mutation, designated $n p f G 2$. The $n p f G$ locus did not show linkage to any of the other $n p f$ loci (Table 6 shows an analysis of progeny from a cross with an $n p f F 1$ strain; see Methods for details). Like $n p f A 1$, the recessive $n p f G 1$ allele apparently had no effect upon sexual development although it blocked apogamic development. In clonal cultures of gad $A 111$ amoebae carrying $n p f G 1$ or $n p f G 2$, plasmodia appeared at a low frequency (about 1 in $10^{6}$ cells) after extended periods of incubation. Tests on the progeny of one such plasmodium indicated that it had arisen by reversion.

Time-lapse cinematography of the $n p f G 1$ mutant showed that amoebal cell cycle lengths and growth were not different from the parental strain, RA376 (Table 7). No cells completed an extended cell cycle and no binucleate cells were observed. Assays of cell proliferation showed 
Table 7. Time-lapse cinematographic analysis

\begin{tabular}{|c|c|c|c|c|}
\hline \multirow[t]{2}{*}{ Measurement } & \multicolumn{4}{|c|}{ Mutant } \\
\hline & $n p f F 2$ & $n p f G 1$ & $n p f K 1$ & $n p f M 1$ \\
\hline & \multicolumn{4}{|c|}{ Cell cycle length $(\mathrm{h}) *$} \\
\hline Amoebal IM'T & $11 \cdot 1 \pm 2 \cdot 1(n=39)$ & $12 \cdot 5 \pm 2 \cdot 0(n=111)$ & $9 \cdot 74 \pm 1.6(n=21)$ & $13.4 \pm 1.6(n=38)$ \\
\hline Length of long cell cycle & $29 \cdot 6 \pm 6 \cdot 2(n=11)$ & - & $22 \cdot 6 \pm 1 \cdot 7(n=11)$ & $29 \cdot 8 \pm 3 \cdot 7(n=4)$ \\
\hline \multirow{2}{*}{$\begin{array}{l}\text { Length of cell cycle following } \\
\text { long cell cycle }\end{array}$} & $12 \cdot 5 \pm 7 \cdot 2(n=6)$ & - & $6 \cdot 0 \pm 1 \cdot 8(n=3)$ & - \\
\hline & \multicolumn{4}{|c|}{ Area $\nmid$} \\
\hline Amoebal area at birth & - & $12 \cdot 2 \pm 2 \cdot 3(n=111)$ & $8 \cdot 6 \pm 1 \cdot 1(n=21)$ & $8 \cdot 9 \pm 1 \cdot 2(n=38)$ \\
\hline Amoebal area at mitosis & - & $27 \cdot 1 \pm 3 \cdot 4(n=111)$ & $18 \cdot 1 \pm 1 \cdot 7(n=21)$ & $19 \cdot 3 \pm 2 \cdot 2(n=38)$ \\
\hline Area at start of long cell cycle & - & - & $8 \cdot 7 \pm 0 \cdot 7(n=110)$ & $8 \cdot 0 \pm 2 \cdot 1(n=4)$ \\
\hline Area at end of long cell cycle & - & - & $37 \cdot 3 \pm 4 \cdot 7(n=11)$ & $38 \cdot 8 \pm 6 \cdot 2(n=4)$ \\
\hline Area at binucleate mitosis & - & - & $59 \cdot 7 \pm 10 \cdot 1(n=3)$ & - \\
\hline
\end{tabular}

* Cell cycle lengths (IMT) are given in hours as mean \pm SD.

† Areas are given in arbitrary units that cannot be compared for different films and are shown as mean $\pm \mathrm{sD}$.

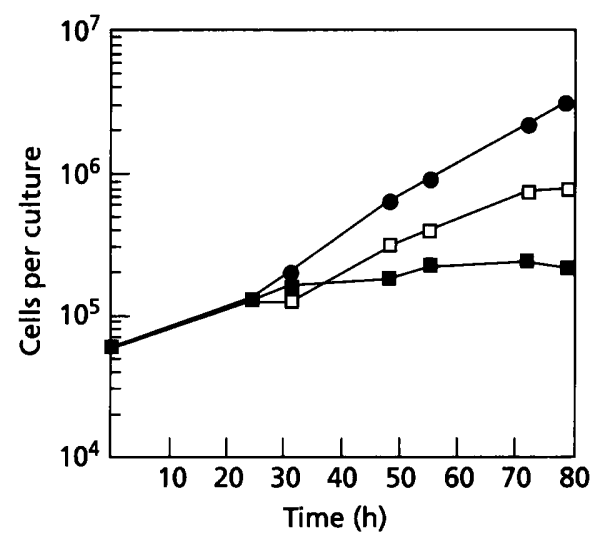

Fig. 1. Cell proliferation at $21^{\circ} \mathrm{C}$ for LU911 ( $n p f G^{+}$gadA $A^{+}$) RA422 (npfG1 gadA111; $\square$ ) and RA376 (npfG gadA111; $\square$ ).

that, at $21^{\circ} \mathrm{C}$, cultures of RA422 amoebae showed a lower rate of proliferation than $\mathrm{gad} \mathrm{A}^{+}$amoebae at this temperature (Fig. 1), whereas at $30^{\circ} \mathrm{C}$ the strains proliferated at the same rate (data not shown). Microscopic examination of $n p f G 1$ cultures revealed a few binucleate cells but no cells with more than two nuclei or containing ingested amoebae (Table 3 ); in $n p f G 2$ cultures, only uninucleate cells were observed. The number of cells able to undergo the amoeba-flagellate transition did not decrease during culture of either $n p f G$ strain (data not shown).

In cultures of cells carrying either of the $n p f G$ mutations, the levels of $\alpha 3$-tubulin-negative cells and cells with multipolar spindles were the same as those observed for vegetative amoebae (Tables 2 and 4). One $\beta 2$-tubulin positive cell was detected among several thousand $n p f G 1$ cells but none were seen in $n p f G 2$ cultures (Table 2). Although no plasmodial spindles were formed, star microtubular arrays were present in up to $15 \%$ of $n p f G$ cells (Fig. 2; Table 4). Analysis of DAPI-stained cells showed that $2 \cdot 4 \%$ of $n p f G 1$ cells $(n=4245)$ and one $n p f G 2$ cell $(n=3131)$ had a single condensed nucleus; no cells with two or more condensed nuclei were observed.

Although star microtubular arrays and condensed nuclei are associated with abnormal development and the cells presumably died, the presence of these markers indicated that some $n p f G$ cells had initiated development. The majority of cells in $n p f G$ cultures show no evidence of development and we conclude that the product of the $n p f G^{+}$gene is normally required at or close to the time that development is initiated.

\section{Mutations causing later blocks in plasmodium development}

npfF. The $n p f F 1$ mutant strain APT1 was isolated by Wheals (1973) after mutagenesis of a gad $A b$ strain and brute force screening. The recessive $n p f \mathrm{~F} 1$ allele blocked both sexual and apogamic plasmodium development. The $n p f F$ locus was found to be unlinked to the developmental loci $n p f A, n p f L$ and mat $A$ (Anderson \& Dee, 1977; Bailey et al., 1992), but closely linked to fus $C$, a locus affecting somatic fusion of plasmodia (Pallotta et al., 1979). Our genetic analyses showed no linkage between $n p f F$ and $n p f G, n p f K$ or $n p f M\left(P>0.05, \chi^{2}\right.$ tests). One of the new mutants, RA739, also isolated after mutagenesis and brute force screening of a gad $A b$ strain, failed to complement tester strains carrying $n p f F 1$, and it was therefore concluded that this strain carried a second mutant allele, designated $n p f F 2$.

Collett et al. (1983) observed large uninucleate cells in developing $n p f F 1$ cultures, suggesting that development was initiated in some cells, but no binucleate cells or plasmodia were reported. At various times during the incubation of $n p f F 1$ (CH818) and $n p f F 2$ (RA739) cultures 

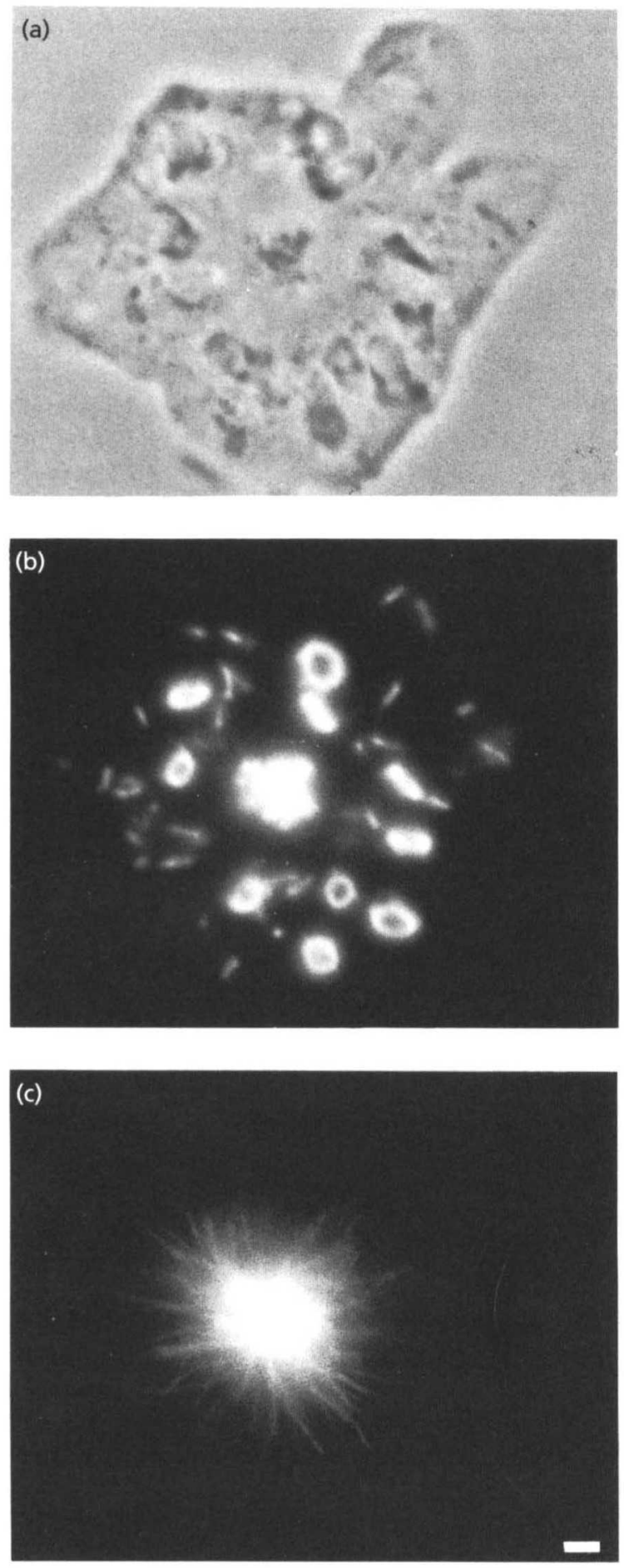

Fig. 2. Star spindles in npfG1. (a) Phase-contrast image of a mitotic npfG1 cell; the condensed chromosomes are visible at the centre of the cell. (b) DAPI image of the same cell showing the condensed chromosomes; the DNA in the mitochondria and ingested bacteria is visible in the cytoplasm. (c) The star microtubular array in the same cell visualized using anti-tubulin antibodies and immunofluorescence microscopy. Bar, $1 \mu \mathrm{m}$.

at $21{ }^{\circ} \mathrm{C}$, we estimated the number of cells per culture and measured the diameters of cells. Large uninucleate cells were defined as cells with diameters greater than the

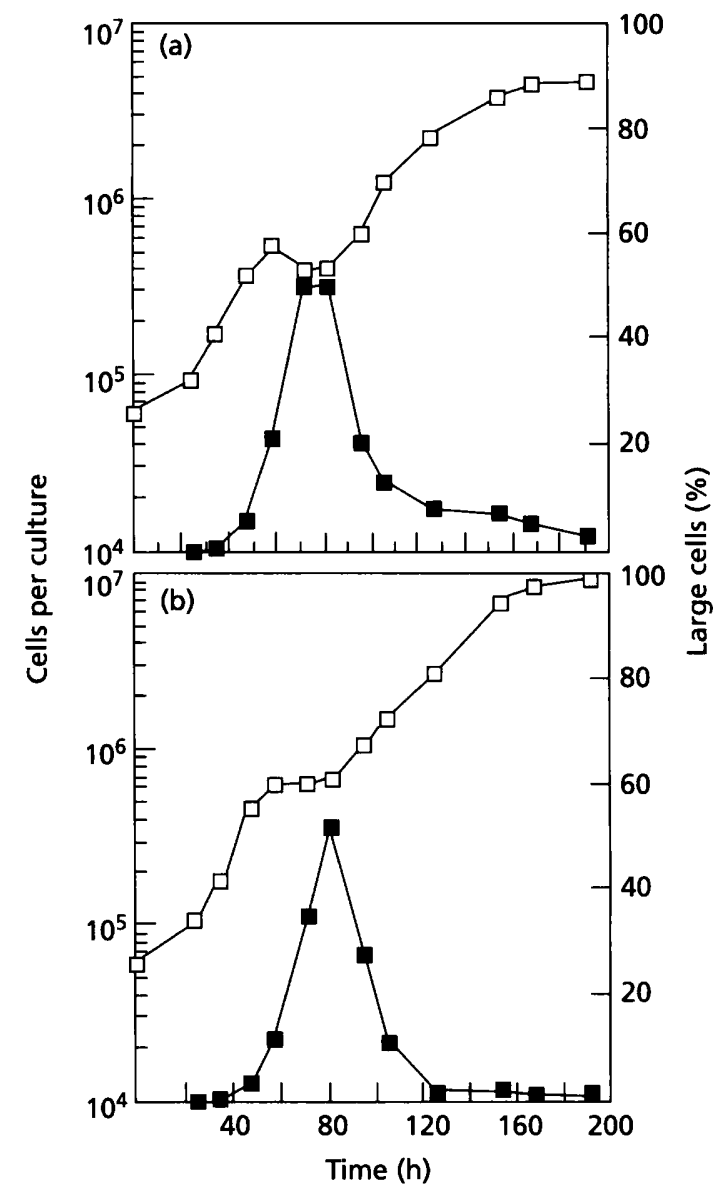

Fig. 3. Cell proliferation and diameter in npfF strains. The number of cells per culture $(\square)$ and the percentage of large cells ( $\square$ ) were measured at different times after incubation at $21^{\circ} \mathrm{C}$ for (a) npff1 and (b) npfF2.

maximum cell diameter recorded at the $24 \mathrm{~h}$ timepoint (Fig. 3). Cell proliferation was initially exponential but cell numbers remained constant or fell between 50 and $90 \mathrm{~h}$, and then increased at a slower rate (Fig. 3). No large uninucleate cells were observed until about $50 \mathrm{~h}$ of incubation, the time at which cell number stopped increasing. The population contained more than $50 \%$ large cells during the period when cell number was not increasing, but the number of large cells declined to less than $10 \%$ of the population when cell proliferation resumed (Fig. 3). The pause in cell proliferation and the increase in cell size suggested that many cells entered the long cell cycle. The resumption of proliferation suggested that the developing cells failed to become binucleate at the end of this cell cycle and instead returned to vegetative amoebal proliferation; the time of disappearance of large uninucleate cells was consistent with this interpretation.

Using time-lapse cinematography, we traced large uninucleate cells of RA739 (npfF2) back to their origins at previous cell divisions and followed their fates through subsequent cell cycles. Measurement of IMTs confirmed that, as in CL (Bailey et al., 1987), one or both daughter cells from an amoebal division could enter an extended 


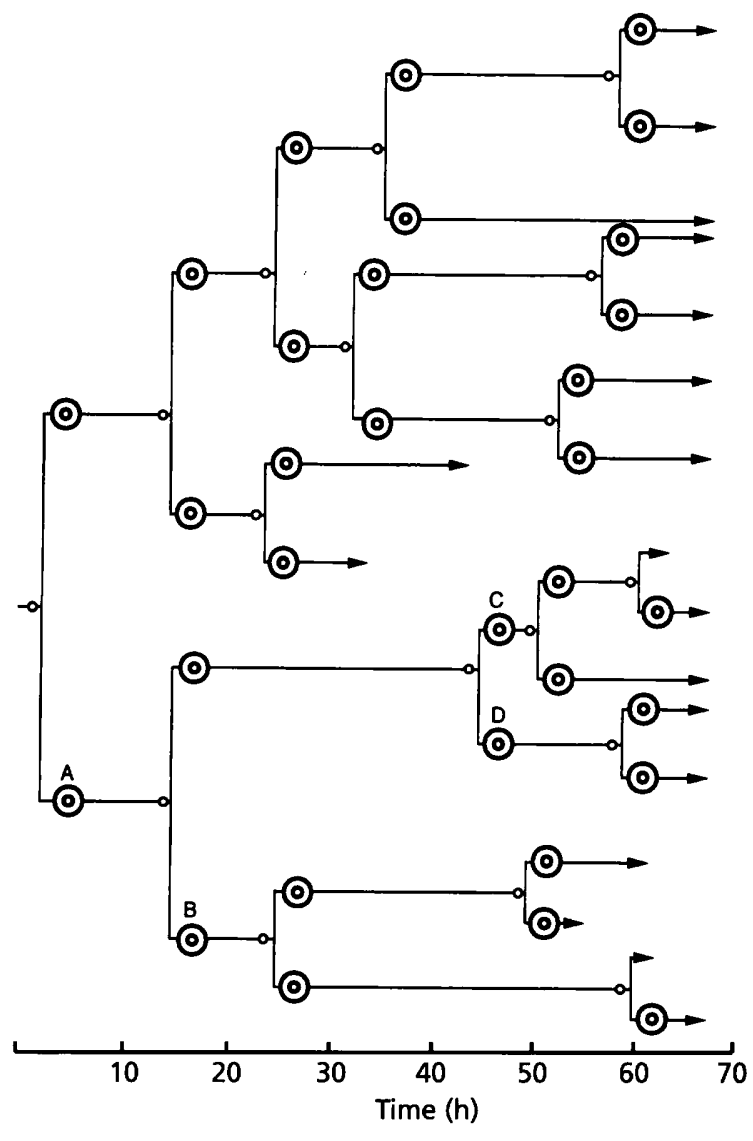

Fig. 4. Representative npfF2 cell pedigree from time-lapse cinematography. Time is given in hours after the start of filming. (-) Uninucleate cell; $O$, time of nucleolar disappearance at start of mitosis; $\rightarrow$, cell left field of view.

cell cycle (Fig. 4, cells A and B) that was more than twice the length of an amoebal cell cycle (Table 7). At the end of this cell cycle, all the large uninucleate cells $(n=11)$ divided instead of becoming binucleate (Fig. 4). In CL, the cell cycle following the extended cell cycle was shorter than an amoebal cell cycle in length (Bailey et al., 1987). In $n p f F 2$, however, the daughter cells resulting from divisions at the end of the long cell cycle went through cell cycles that varied in length, from about 0.7 of an amoebal cell cycle to more than twice an amoebal cell cycle (Fig. 4, cells $\mathrm{C}$ and $\mathrm{D}$; Table 7) before dividing to give two uninucleate daughters. None of the cells gained the plasmodial characteristics of chasing or ingesting amoebae, or fusing with other developing cells.

Microscopic examination of DAPI-stained $n p f \mathrm{~F} 1$ cells showed that a small proportion (up to $0.8 \%$ ) of cells were binucleate, but neither uninucleate cells that ingested other cells, nor cells with four or more nuclei were detected (Table 3). No plasmodia ever formed in cultures of this strain even after extended culture. A few cells (up to $3.8 \%, n=2446$ ) showed condensed nuclei. Up to a quarter of $n p f F 1$ cells lost detectable levels of $\alpha 3$-tubulin, and up to a third exhibited $\beta 2$-tubulin in their microtubular structures (Fig. 5; Table 2). Mitotic spindles of the plasmodial type were observed in some cells; presumably at least some of these gave rise to binucleate cells. Star microtubular arrays were also observed (Table 4). Some $n p f F 1$ cells contained abnormally thick, sinuous microtubules exhibiting $\alpha 3$-tubulin along their lengths (Fig. 6). Such a distribution of $\alpha 3$-tubulin has not been previously observed in Pbysarum, although microtubules of similar morphology, but lacking $\alpha 3$-tubulin, are characteristic of the $n p f L 1$ mutant (Bailey et al., 1992a).

Our analyses indicated that development was initiated in many cells carrying an $n p f F$ mutation but was blocked close to the end of the long cell cycle. The majority of uninucleate cells divided at the end of an extended cell cycle, and apparently resumed proliferative growth, although we cannot be sure that they were normal amoebae in all respects. The presence of star spindles suggested that some cells died at the end of the long cell cycle instead of returning to the proliferative state. The binucleate cells that formed did not develop into plasmodia, and the presence of cells with condensed nuclei suggests that they died by an apoptosis-like mechanism. Since most $n p f F$ cells failed to become binucleate at the end of the long cell cycle, the product of the $n p f \mathrm{~F}^{+}$gene must have become essential for normal development at, or before, the time at which developing uninucleate cells entered the mitosis at the end of the extended cell cycle.

npfK. RA612 was isolated following mutagenesis of $\operatorname{gad} A b$ $\mathrm{CL}$ amoebae and brute force screening. This strain carried a single recessive nuclear gene mutation, $n p f K 1$, that was unlinked to $n p f A, n p f F, n p f G, n p f \mathrm{~L}$ and mat $A$ (data not shown). Recombination between $n p f K$ and $n p f M$ was not tested, but strains carrying these two mutations complemented each other, and it was concluded that $n p f K 1$ and $n p f M 1$ were non-allelic. The $n p f K$ locus and $s a x A$, a locus affecting growth of plasmodia on axenic media (Poulter, 1969), were located on either side of $f u s A$, a locus affecting plasmodial fusion. The recombination frequency between $n p f K$ and $f u s A$ was $16.8 \%$ (54 recombinants: 167 parentals). The $n p f K 1$ mutation affected both apogamic and sexual plasmodium development. Development in this mutant was blocked at a late stage of plasmodium formation. Macroscopic cells with an unusual morphology arose (Fig. 7a); these contained only a few hundred nuclei and did not exhibit the characteristic reticulate morphology of normal plasmodia.

In cultures of RA612 at $22{ }^{\circ} \mathrm{C}$, cell number increased exponentially and then fell in the same way as in CL cultures (Bailey et al., 1987). As cell number increased, the proportion of cells that could transform into flagellates decreased, and the frequency of binucleate cells increased (Fig. 8). The efficiency of plating decreased during culture, indicating that many cells lost the ability to grow as amoebae (Fig. 8). Binucleate and multinucleate cells were present but exhibited a unique stringy morphology (Table 3; Fig. 7); when harvested from plates, these cells were more fragile than CL multinucleate cells.

Time-lapse filming showed no obvious differences between RA612 and CL in amoebal growth or division, development to the end of the long cell cycle, or the 

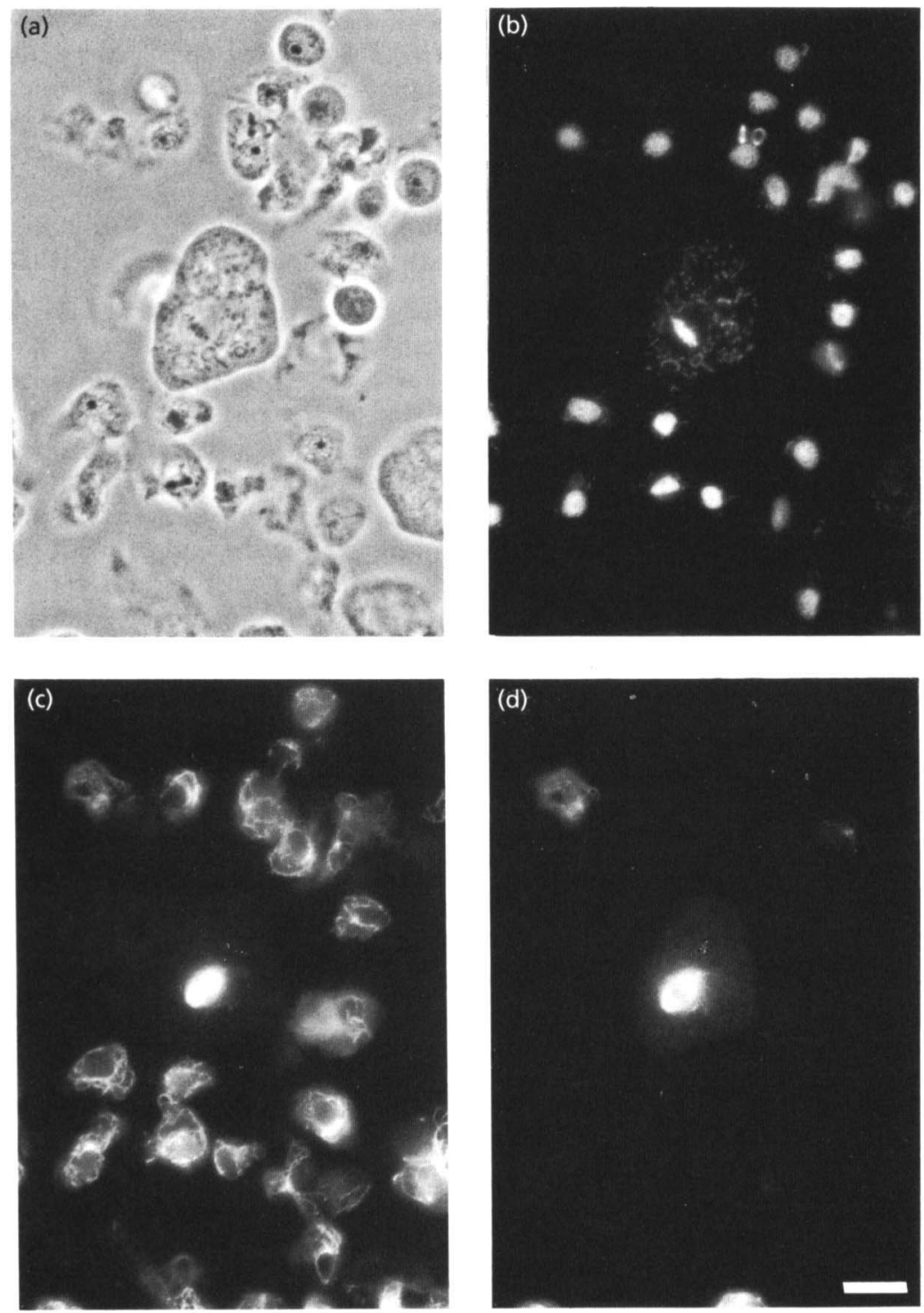

Fig. 5. Tubulin in npff1 cells. (a) Phasecontrast image of cells from a developing culture; the large uninucleate cell in the centre has condensed chromosomes on a metaphase plate. (b) DAPI image of the same field; the metaphase plate in the large cell is visible, as is the DNA in the mitochondria and ingested bacteria. (c) The same field stained with a general $\beta$-tubulin antibody; the spindle in the large cell is clearly visible, as are the microtubles in the other cells. (d) The same field stained with a $\beta 2$-tubulin specific antibody; most cells show no staining but the spindle is $\beta 2$-tubulin positive. Bar, $10 \mu \mathrm{m}$. length of the following cell cycle (Fig. 9; Table 7; Bailey et al., 1987). After the end of the extended cell cycle, differences were observed between $\mathrm{CL}$ and the $n p f \mathrm{~K} 1$ mutant; little locomotion was observed in $n p f K 1$ multinucleate cells, although they continually extended and retracted pseudopodia. Several pseudopodia were often extended at once, in different directions, giving rise to irregularly-shaped fissured cells (Fig. 7a). Sections of these cells were joined by thin bridges of cytoplasm that frequently broke. Multinucleate $n p f K 1$ cells rarely fused with one another, only occasionally ingested amoebae and did not show the rhythmic pulsations characteristic of plasmodia of this size. At the same stage of development, CL plasmodia were thick and rounded, fused together frequently, and ingested many amoebae (Bailey et al., 1987).

Immunofluorescence microscopy showed that the chan- ges in microtubule organization that occurred during multinucleate cell formation in $n p f K 1$ were very similar to those observed for CL (Solnica-Krezel $e$ t al., 1990, 1991). Plasmodial mitotic spindles and star microtubular arrays were detected (Table 4), as were cells that had become $\beta 2$-tubulin positive (Table 2, Fig. 7).

Wild-type plasmodia cultured in SDM liquid in shaken culture grow in the form of rounded, non-reticulate microplasmodia containing several hundred nuclei. When blocks of agar carrying multinucleate $n p f K 1$ cells were placed in this medium, the cells migrated into the medium and grew in shaken culture with apparently normal microplasmodial morphology and growth rate. Like CL microplasmodia, $n \not f K 1$ cells from SDM liquid cultures rapidly fused together when placed on SDM agar to give apparently normal macroplasmodia. When spores from four of these plasmodia were allowed to germinate, all the 

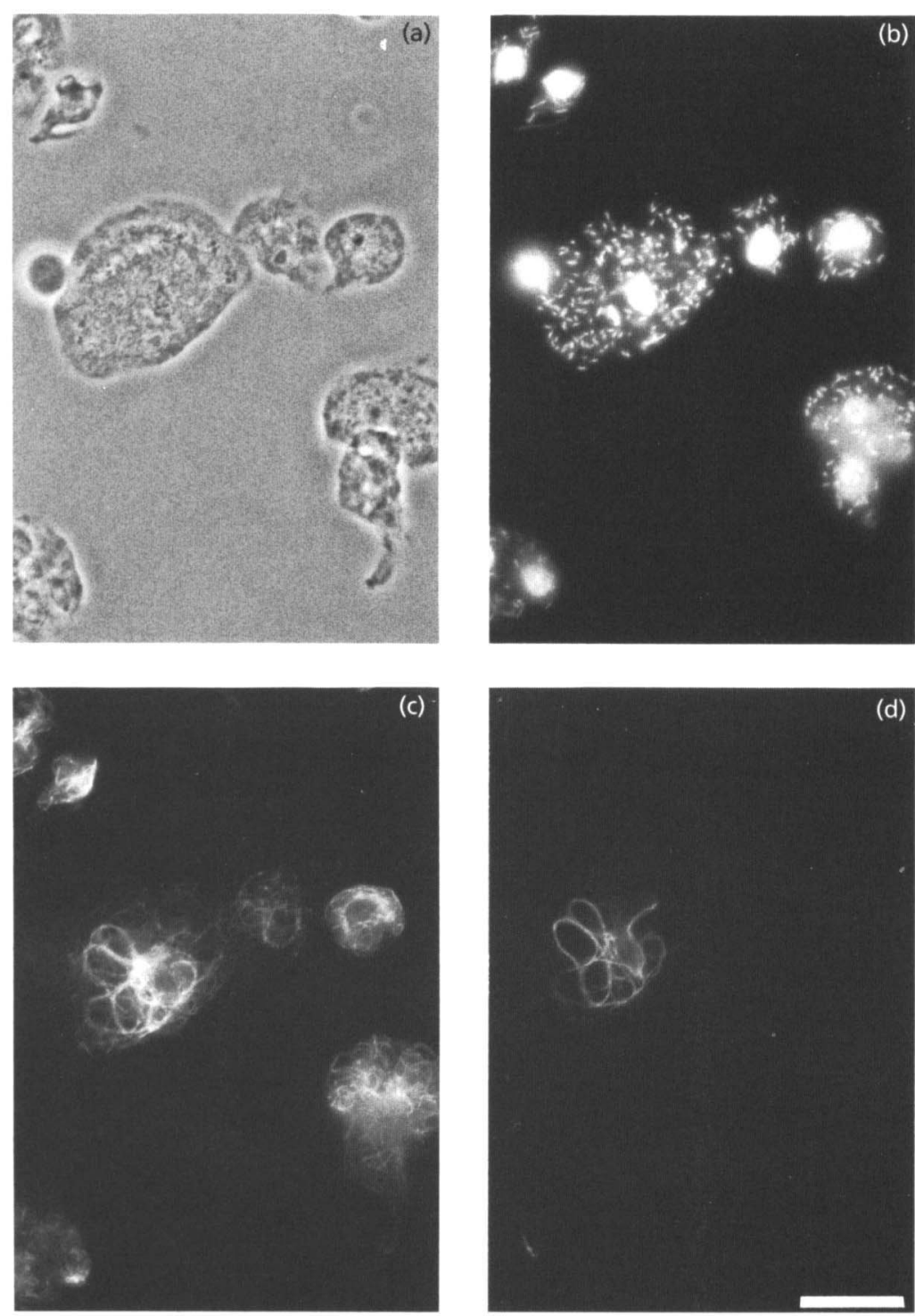

Fig. 6. Unusual distribution of $\alpha 3$-tubulin in an npfF1 cell. (a) Phase-contrast image of npfF1 cells from a developing culture. (b) DAPI image of the same field; the DNA in mitochondria and ingested bacteria is visible in the cytoplasm. (c) The same field stained with a general $\beta$-tubulin antibody; the microtubules in the large uninucleate cell are thicker than those in other cells. (d) The same field stained with the $\alpha 3$-tubulin specific antibody; $\alpha 3$-tubulin is present in the microtubules of the large uninucleate cell. Bar, $10 \mu \mathrm{m}$. resultant colonies gave rise to cells with the characteristic $n p f K 1$ morphology. Thus development of macroplasmodia was not due to reversion of the mutation.

Since abnormalities in development were first observed immediately after the end of the long cell cycle, the wildtype gene product must become essential for development at, or before, this time. Development did not cease immediately after abnormal features were observed, but continued for some cell cycles even though the multinucleate cells exhibited an abnormal phenotype. The low level of plasmodial fusions suggests that one effect of the $n p f K 1$ mutation may be on some aspect of plasmodial membrane structure.

npfM1. RA613 was isolated following mutagenesis of CL amoebae and brute force screening. This strain carried a single recessive nuclear gene mutation, $n p f M 1$, unlinked to $n p f A, n p f F, n p f G, n p f L$ and mat $A$. The mutation affected both apogamic and sexual plasmodium development. Mutant cultures on plates or in filming slides gave rise to small multinucleate cells, which were not obviously abnormal in morphology but apparently remained in close contact without fusing (Fig. 10). Multinucleate cells were first detected later after inoculation than in $n p f K 1$ and CL. No macroplasmodia formed even after extended culture.

Measurements of cell cycle lengths in time-lapse films showed that $n p f M 1$ amoebae grew significantly more slowly than amoebae of the parental strain, RA376 (Student's $t$-test, $P=0.01$; Table 7 ). This observation suggests that the $n p f M 1$ mutation may have a minor effect on amoebal proliferation in addition to its major effect on plasmodium development. Four cells were observed to undergo the extended cell cycle and become binucleate. The first binucleate cell was observed about $24 \mathrm{~h}$ later 

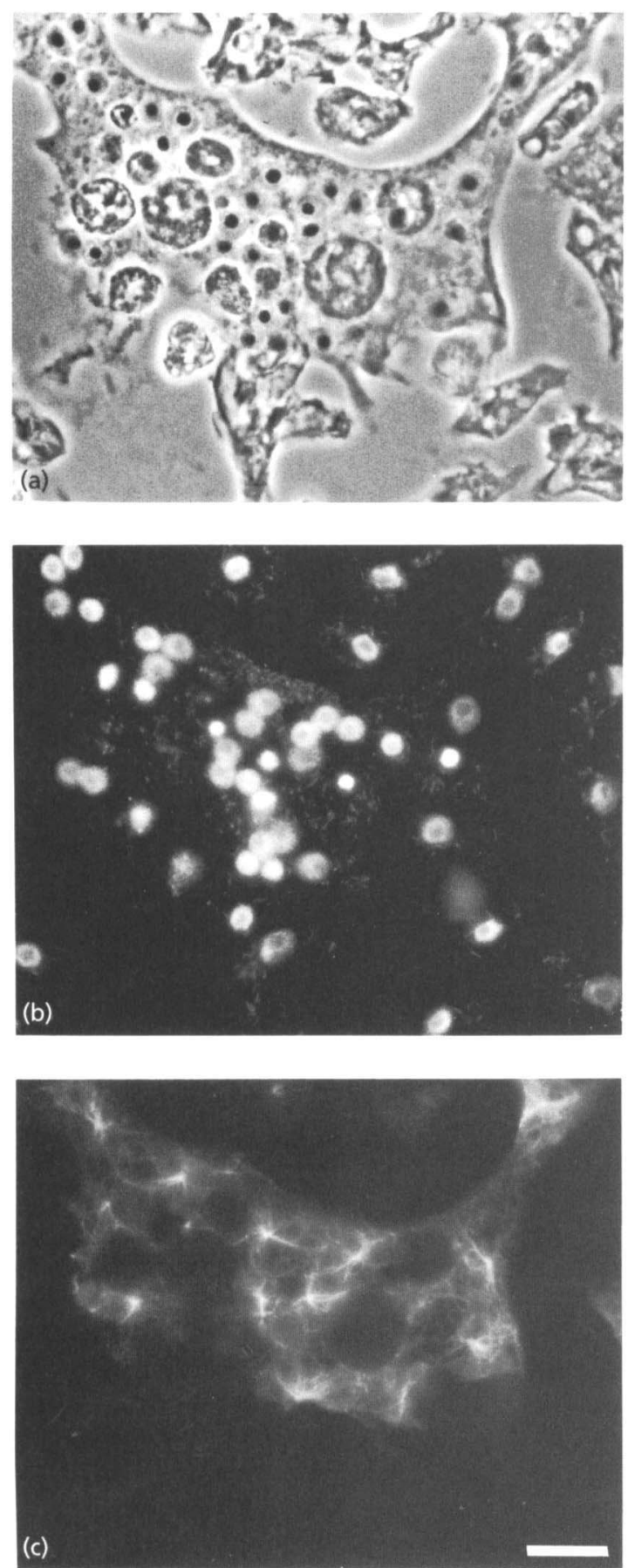

Fig. 7. Cellular morphology and $\beta 2$-tubulin expression in a multinucleate npfK cell. (a) Phase-contrast image of a multinucleate cell containing ingested amoebae; note the unusual shape of the cell. (b) DAPI image of the same cell; the nuclei of the cell and of ingested cells stain, as do mitochondria and ingested bacteria. (c) $\beta 2$-tubulin staining in the same cell. Bar, $10 \mu \mathrm{m}$.

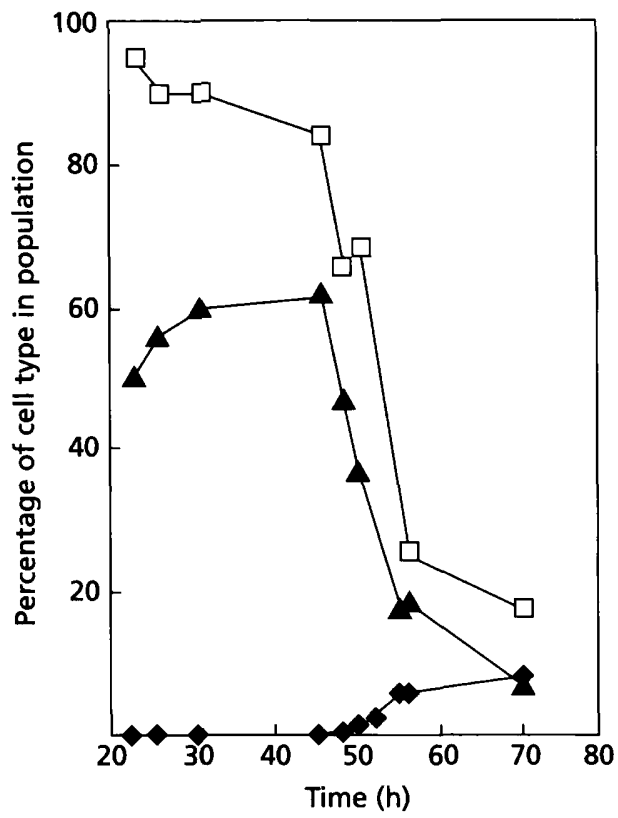

Fig. 8. Development in npfK. The percentage of cells able to transform into flagellates $(\square)$, the percentage of binucleate cells $(\boldsymbol{\Delta})$ and the efficiency of plating $(\boldsymbol{A})$ were measured at various times after incubation at $21^{\circ} \mathrm{C}$.
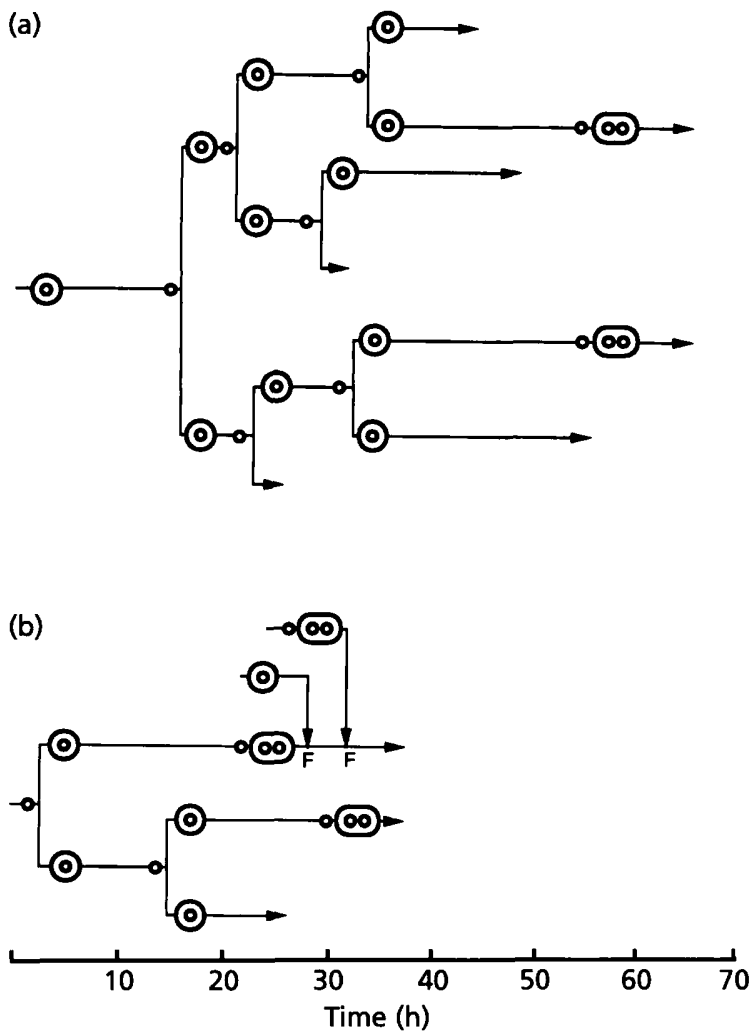

Fig. 9. (a, b) Two representative $n p f K 1$ cell pedigrees from time-lapse cinematography. Time is given in hours after the start of filming, $F$, cell fusion, $\bigcirc$. binucleate cell; all other symbols as in Fig. 4. 


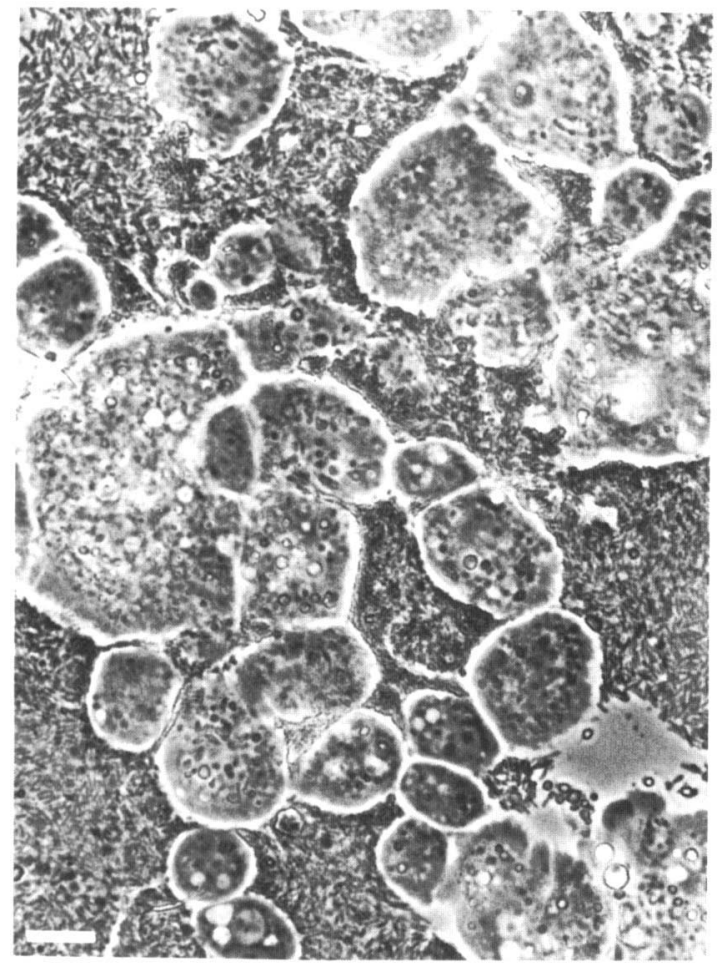

Fig. 10. Phase-contrast image of multinucleate mpfM1 cells. Bar, $10 \mu \mathrm{m}$.

than the first binucleate cells seen in CL (Bailey et al., 1987); this may be a consequence of the slower proliferation rate of $n D f M 1$ amoebae. No obvious morphological abnormalities were observed in the binucleate cells but, in contrast to CL developing cells, RA613 developing cells did not ingest amoebae, or fuse with one another.

Immunofluorescence microscopy of developing $n p f M 1$ cells labelled with tubulin-specific antibodies showed a pattern similar to that observed in CL (Solnica-Krezel et al., 1990, 1991). The majority of developing $n p f M 1$ cells exhibited $\beta 2$-tubulin in their microtubules, and in some cells $\alpha 3$-tubulin was not detectable (Table 2). Plasmodial spindles were observed in many cells, and star and multipolar spindles occurred at low frequency (Table 4). Up to $17 \%$ of all DAPI-stained cells $(n=2912)$ and $46 \%$ of DAPI-stained binucleate cells $(n=488)$ contained condensed nuclei. The presence of many cells with condensed nuclei suggests that developing $n p f M 1$ cells eventually die by an apoptosis-like mechanism.

Since unusual events in development were first observed immediately after the end of the long cell cycle, the wildtype gene product must become essential for development at, or before, the end of this cell cycle. The absence of fusion and phagocytosis suggests that the $n p f M 1 \mathrm{mu}-$ tation, like the $n p f K 1$ mutation, has an effect on some aspect of plasmodial membrane structure.

\section{Development in double mutant strains}

To investigate the interactions between $n p f$ genes, we studied the phenotypes of double mutant strains obtained as progeny of crosses between the $n p f$ mutants (e.g. see Table 6).

npfF1 npfG1. Where there was a difference in the phenotypes of the $n p f F 1$ and $n p f G 1$ strains, the double mutant (RA545) resembled $n p f G 1$ rather than $n p f F 1$; thus $n p f G 1$ is epistatic to $n p f F$. For example, no $\beta 2$-tubulin positive cells were detected and $\alpha 3$-tubulin was detectable in almost all cells (Table 2). Most spindles were amoebal, although there was a low level of star microtubular arrays, and a small proportion of multipolar (amoebal-tripolar) spindles (Table 4). No plasmodial spindles were observed in uninucleate cells. These results suggest that the $n p f G^{+}$ and $n p f \mathrm{~F}^{+}$gene products may act sequentially in the same pathway.

npfK1 npfL1. The double mutant (RA775) showed characteristics of both single mutants, suggesting that $n p f K 1$ and $n p f L 1$ acted in separate pathways and that neither mutation was epistatic to the other. The morphology of the $n p f K 1 n p f \mathrm{~L} 1$ multinucleate cells was similar to the abnormal morphology of $n p f K 1$ cells at the same stage of development. The frequencies of uninucleate developing cells with abnormal star and multipolar spindles were higher for the double mutant than those observed for $n p f K 1$ (Table 4), and similar to those previously observed for $n p f L 1$, which apparently has a defect in nuclear structure (Bailey et al., 1992). Cells with condensed nuclei constituted up to $10 \%$ of cells $(n=2501)$ in some cultures, as seen in $n p f L 1$ developing cultures (Bailey et al., 1992a) but not in $n p f K 1$. Plasmodia never arose in cultures of the double mutant and the cultures lacked the yellow macroscopic cells characteristic of the $n p f \mathrm{~K}$ mutant.

\section{GENERAL DISCUSSION}

The brute force method has been successful in identifying a number of new genes required for plasmodium development. The mutants isolated using an enrichment step prior to screening are almost all of the $n p f B$ and $n p f C$ classes and closely linked to the mat $A$ locus (e.g. Davidow \& Holt, 1977; Anderson et al., 1989). Although comparatively few $n \not f$ mutants have been isolated by screening without prior enrichment, these have already identified several $n p f$ genes unlinked to mat $A$; for example, $n p f F$ (Wheals, 1973), $n p f L$ (Bailey et al., 1992a), $n p f G, n p f K$ and $n p f M$. Since nearly 1 in 1000 colonies derived from mutagenized amoebae may carry an $n p f$ mutation (R. W. Anderson, unpublished data), it is clearly feasible to isolate large numbers of $n p f$ mutants without using enrichment. As only one or two mutant alleles have so far been identified at each locus, further brute force screening should lead to the identification of many more $n p f$ genes.

Unlike the mutants isolated by the enrichment method, which were all blocked close to initiation of plasmodium development, the $n p f$ mutants described in the present paper differed widely in phenotype. Several mutants $(n p f F, n p f K 1$ and $n p f M 1$, and the $n p f L 1$ mutant described 
by Bailey et al., 1992a) first showed abnormalities in development around the time of binucleate cell formation, suggesting that the wild-type genes begin to function at or before this time. These results are consistent with previous observations that extensive changes in cellular organization and gene expression begin during the long cell cycle, prior to binucleate cell formation (Bailey et al., 1987, 1992a; Sweeney et al., 1987). These four mutants had very different terminal phenotypes, suggesting that the wild-type genes functioned in different developmental pathways. Further evidence for multiple developmental pathways was provided by our observations that some aspects of plasmodium development occurred normally in the mutants even though other functions were blocked; for example, developing cells of the $n p f K 1$ and $n p f M 1$ mutants expressed the plasmodium-specific $\beta 2$-tubulin isotype, but underwent few or no plasmodial fusions. We conclude that these plasmodial characteristics are not dependent on one another, although they are normally acquired at the same time. Our previous analyses of apogamic development in CL also suggested that independent pathways are involved in plasmodium development (Solnica-Krezel et al., 1990).

Phenotypic analysis of development in double mutants allowed investigation of epistatic interactions between different $n p f$ genes. For example, the $n p f K 1 n p f L 1$ double mutant showed features of both the $n p f K 1$ and $n p f \mathrm{~L} 1$ single mutants, suggesting that these two genes acted in different pathways. In contrast, the $n p f \mathrm{~F} 1 n p f G 1$ double mutant had a phenotype similar to that of $n p f G 1$, suggesting that the wild-type genes acted sequentially in a single pathway. Even though we have examined few double mutants so far, they have provided evidence for both dependent and independent events. Our results indicate that phenotypic studies of further $n p f$ mutants and additional double-mutant combinations will be productive in elucidating the pathways involved in plasmodium development in Pbysarum.

In mutant $n p f L 1$ cells, abnormal development terminates in apoptosis-like cell death (Bailey et al., 1992a). Cells with condensed nuclei, similar to those seen in the dying npfL1 cells, were also seen in several other $n p f$ mutants (e.g. $n p f G, n p f F, n p f M)$ at the terminal stages of differentiation. These observations suggest that, regardless of the primary lesion, inability to complete plasmodium development may result in apoptosis-like cell death. Since apoptosis has been interpreted as a mechanism that has evolved because of its value to multicellular organisms (Vaux et al., 1994), we are interested that the same process may be occurring in a unicellular organism; further investigations of this possibility are in progress.

All the $n p f$ mutants studied in the present paper were isolated because they were blocked in apogamic development. Mutations in three of the genes $(n p f F, n p f K$ and $n p f M$ ) blocked sexual as well as apogamic development. This is not surprising, because mutations in these three genes affected only the later stages of plasmodium formation, and our previous observations showed that the same sequence of cellular events is common to the later stages of both sexual and apogamic development (Bailey et al., 1987, 1990).

Unlike mutations in $n p f F, n p f K$ and $n p f M$, the $n p f A$ and $n p f G$ mutations differed in their effects on sexual and apogamic development. These mutations apparently had no effect on sexual development although they blocked apogamic development at a very early stage, close to the time of initiation. The major difference between sexual and apogamic development is in the initiation process: sexual development is initiated by the formation of a fusion cell heteroallelic for mat $A$, whereas apogamic development is initiated, without cell fusion, in cells carrying a mutation in the mat $A$ gad $A$ genetic region. It therefore seems possible that the mutations in $n p f A$ and $n p f G$ interfere with the initiation process in apogamic development but not in sexual development. Since all natural isolates of $P$. polycephalum exhibit sexual development, however, it seems unlikely that the wild-type alleles of $n p f A$ and $n p f G$ have no function in sexual strains. If the mutant $n p f A 1, n p f G 1$ and $n p f G 2$ alleles code for products with partial function, their functions may be sufficient when development is initiated by the wild-type sexual mechanism, but insufficient for the initiation of apogamic development. The temperature sensitivity of development in $n p f A 1$ mutants (Anderson \& Dee, 1977) indicates that this allele is not a null mutation. Before we can be certain that the wild-type alleles of $n p f A$ and $n p f G$ have no role in the initiation of sexual development, it will be necessary to study mutants carrying null alleles of these loci.

With the possible exception of $n p f M 1$ amoebae, the mutant $n p f$ strains showed normal amoebal growth, suggesting that the wild-type genes are not required in vegetative amoebae under the conditions used, but are switched on during plasmodium development. It is possible that some of the genes function transiently during development whereas others may be required throughout plasmodial growth. For the majority of mutants, there is no clear evidence to indicate whether the genes are switched off when development is complete. For the temperature-sensitive $n p f A 1$ mutant, however, Anderson \& Dee (1977) showed that non-revertant plasmodia formed at $22{ }^{\circ} \mathrm{C}$ grew normally at $32{ }^{\circ} \mathrm{C}$; this suggests that the wild-type gene is not required for plasmodial growth under the conditions used. In the present study, multinucleate cells of the $n p f K 1$ mutant, in which development was blocked at a late stage, gave rise to non-revertant macroplasmodia when cultured in liquid axenic medium, suggesting that the wild-type gene is not required for plasmodial growth in this medium, although it may be required in other conditions.

As an approach to identifying genes specifically required for plasmodium development rather than growth, we are screening a subtracted cDNA library made from developing cultures (Bailey et al., 1992b). Recently developed methods for DNA transformation in Pbysarum (Burland $e t$ al., 1992a, b, 1993) will allow us to use gene disruption to investigate the functions of these transition-specific genes. These experiments will generate new $n p f$ mutants which 
will be analysed by the methods described in this paper. This combination of classical and molecular genetic approaches with cytological analyses of phenotypes should help to elucidate the cellular and molecular mechanisms of plasmodium development.

\section{ACKNOWLEDGEMENTS}

J.B., R. W. A. and J. D. are grateful to the SERC for financial support (Grant no. GR/D34530). L. S.-K. wishes to acknowledge support from Core Grant CA-07175 and the Program Project Grant in Tumor Biology CA-23076 from the National Cancer Institute. L.S.-K. was also supported by a Wisconsin Power and Light Foundation Fellowship in Cancer Research dedicated to the memory of employees and retirees of Wisconsin Power and Light Company who suffered or died as a result of cancer.

\section{REFERENCES}

Anderson, R. W. (1979). Complementation of amoebal-plasmodial transition mutants in Physarum polycephalum. Genetics 91, 409-419.

Anderson, R. W. \& Dee, J. (1977). Isolation and analysis of amoebal-plasmodial transition mutants in the myxomycete Pbysarum polycephalum. Genet Res Camb 29, 21-34.

Anderson, R. W. \& Holt, C. E. (1981). Revertants of selfing (gad) mutants in Pbysarum polycephalum. Dev Genet 2, 253-267.

Anderson, R. W., Hutchins, G., Gray, A., Price, J. \& Anderson, S. E. (1989). Regulation of development by the mat $A$ complex locus in Pbysarum polycephalum. J Gen Microbiol 135, 1347-1359.

Bailey, J., Anderson, R. W. \& Dee, J. (1987). Growth and differentiation in relation to the cell cycle in Pbysarum polycepbalum. Protoplasma 141, 101-111.

Bailey, J., Anderson, R. W. \& Dee, J. (1990). Cellular events during sexual development from amoeba to plasmodium in the slime mould Physarum polycephalum. J Gen Microbiol 135, 739-751.

Bailey, J., Solnica-Krezel, L., Anderson, R. W. \& Dee, J. (1992a). A developmental mutation ( $n p f L 1$ ) resulting in cell death in Pbysarum polycephalum. J Gen Microbiol 138, 2575-2588.

Bailey, J., Solnica-Krezel, L., Lohman, K., Dee, J., Anderson, R. W. \& Dove, W. F. (1992b). Cellular and molecular analysis of plasmodium development in Pbysarum. Cell Biol Int Rep 16, 1083-1090.

Birkett, C. R., Foster, K. E., Johnson, L. \& Gull, K. (1985). Use of monoclonal antibodies to analyze the expression of a multi-tubulin family. FEBS Lett 187, 211-218.

Blindt, A. B., Chainey, A. M., Dee, J. \& Gull, K. (1986). Events in the amoebal-plasmodial transition of Physarum polycephalum studied by enrichment for committed cells. Protoplasma 132, 149-159.

Burland, T. G., Chainey, A. M., Dee, J. \& Foxon, J. L. (1981). Analysis of development and growth in a mutant of Pbysarum polycephalum with defective cytokinesis. Dev Biol 85, 26-38.

Burland, T. G., Schedl, T., Gull, K. \& Dove, W. F. (1984). Genetic analysis of resistance to benzidimazoles in Pbysarum: differential expression of $\beta$-tubulin genes. Genetics 108, 123-141.

Burland, T. G., Paul, E. C. A., Oetliker, M. \& Dove, W. F. (1988). A gene encoding the major beta-tubulin of the mitotic spindle in Physarum polycephalum plasmodia. Mol Cell Biol 8, 1275-1281.

Burland, T. G., Bailey, J., Adam, L., Mukhopadhyay, M. J., Dove, W. F. \& Pallotta, D. (1992a). Transient expression in Physarum of a chloramphenicol acetyltransferase gene under the control of actin gene promoters. Curr Genet 21, 393-398.
Burland, T. G., Bailey, J., Dove, W. F., Mukhopadhyay, M. J. \& Pallotta, D. (1992b). Methods for transient and stable expression of heterologous genes in Physarum. Cell Biol Int Reps 16, 1111-1117.

Burland, T. G., Bailey, J., Pallotta, D. \& Dove, W. F. (1993). Stable, selective, integrative DNA transformation in Pbysarum. Gene 132, 207-212.

Collett, J. I., Holt, C. E. \& Huttermann, A. (1983). Plasmodium formation in Physarum polycephalum: cytological events and their timing relative to commitment. Cell Biol Int Rep 7, 819-825.

Cooke, D. J. \& Dee, J. (1974). Plasmodium formation without change in nuclear DNA content in Physarum polycephalum. Genet Res 23, 307-317.

Davidow, L. S. \& Holt, C. E. (1977). Mutants with decreased differentiation to plasmodia in Physarum polycephalum. Mol \& Gen Genet 155, 291-300.

Dee, J. (1986). The culture of Physarum amoebae in axenic media. In The Molecular Biology of Physarum polycephalum, pp. 255-270. Edited by W. F. Dove, J. Dee, S. Hatano, F. B. Haugli \& K.-E. WolfarthBottermann. New York: Plenum Press.

Dee, J. (1987). Genes and development in Physarum polycephalum. Trends Genet 3, 208-213.

Diggins, M. \& Dove, W. F. (1987). Distribution of acetylated $\alpha$ tubulin in Physarum polycephalum. J Cell Biol 104, 303-309.

Diggins-Gilicinski, M., Solnica-Krezel, L., Burland, T. G., Paul, E. C. A. \& Dove, W. F. (1989). The localization of the divergent $\beta 2$ tubulin isotype in the microtubular arrays of Physarum polycephalum. J Cell Sci 94, 217-226.

Green, L. L. \& Dove, W. F. (1984). Tubulin proteins and RNA during the myxamoeba-flagellate transformation of Physarum polycephalum. Mol Cell Biol 4, 1706-1711.

Havercroft, J. C. \& Gull, K. (1983). Demonstration of different patterns of microtubule organization in Pbysarum polycepbalum myxamoebae and plasmodia using immunofluorescence microscopy. Eur J Cell Biol 32, 67-74.

Honey, N. K., Poulter, R. T. M \& Teale, D. M. (1979). Genetic regulation of differentiation in Physarum polycephalum. Genet Res 34, 131-142.

Honey, N. K., Poulter, R. T. M \& Aston, R. J. (1982). Non-selfing mutants from selfing ( $\mathrm{Het}^{-}$) strains of Physarum polycephalum. Genet Res 39, 261-273.

Kawano, S., Kuroiwa, W. \& Anderson, R. W. (1987). A third multiallelic mating-type locus in Pbysarum polycephalum. $J$ Gen Microbiol 133, 2539-2546.

Nusslein-Volhard, C. \& Wieschaus, E. (1980). Mutations affecting segment number and polarity in Drosopbila. Nature 287, 795-801.

Mullins, M. C. \& Nusslein-Volhard, C. (1993). Mutational approaches to studying embryonic pattern formation in the zebrafish. Curr Opin Genes Dev 3, 648-654.

Pallotta, D. J., Youngman, P. J., Shinnick, T. M. \& Holt, C. E. (1979). Kinetics of mating in Physarum polycephalum. Mycologia 71, 68-84.

Piperno, G. \& Fuller, M. T. (1985). Monoclonal antibodies specific for an acetylated $\alpha$-tubulin in mammalian cells in culture. $J$ Cell Biol 101, 2085-2094.

Poulter, R. T. M. (1969). Senescence in the myxomycete Pbysarum polycephalum. PhD thesis, University of Leicester, UK.

Sasse, R., Glyn, M. C. P., Birkett, C. R. \& Gull, K. (1987). Acetylated $\alpha$-tubulin in Physarum: immunological characterization of the isotype and its usage in particular microtubular organelles. $J$ Cell Biol 104, 41-49.

Solnica-Krezel, L., Dove, W. F. \& Burland, T. G. (1988). Activation 
of a $\beta 2$-tubulin gene during early development of the plasmodium in Pbysarum polycephalum. J Gen Microbiol 134, 1323-1331.

Solnica-Krezel, L., Diggins-Gilicinski, M., Burland, T. G. \& Dove, W. F. (1990). Variable pathways for developmental changes in composition and organization of microtubules in Physarum polycephalum. J Cell Sci 96 383-393.

Solnica-Krezel, L., Burland, T. G. \& Dove, W. F. (1991). Variable pathways for developmental changes in mitosis and cytokinesis in Physarum polycephalum. J Cell Biol 113, 591-604.

Sweeney, G. E., Watts, D. I. \& Turnock, G. (1987). Differential gene expression during the amoebal-plasmodial transition in Physarum. Nucleic Acids Res 15, 933-945.

Uyeda, T. Q. \& Kohama, K. (1987). Myosin switching during amoebo-plasmodial differentiation of slime mold, Pbysarum polycephalum. Exp Cell Res 169, 74-84.
Vaux, D. L., Haecker, G. \& Strasser, A. (1994). An evolutionary perspective on apoptosis. Cell 76, 777-779.

Walden, P. D., Blindt, A. B., Birkett, C. R., Cox, R. A. \& Gull, K. (1989). Recognition of specific Physarum $\alpha$-tubulin isotypes by a monoclonal antibody. Eur J Biochem 185, 383-389.

Wheals, A. E. (1973). Developmental mutants in a homothallic strain of Physarum polycephalum. Genet Res 21, 79-86.

Wyllie, A. H. (1988). Apoptosis. ISI Atlas Sci Immunol 1, 192-196. Youngman, P. J., Adler, P. N., Shinnick, T. M. \& Holt, C. E. (1977). An extracellular inducer of asexual plasmodial development in Physarum polycephalum. Proc Natl Acad Sci US A 74, 1120-1124.

Received 7 October 1994; accepted 3 January 1995. 